\title{
The CU ground MAX-DOAS instrument: characterization of RMS noise limitations and first measurements near Pensacola, FL of BrO, IO, and CHOCHO
}

\author{
S. Coburn ${ }^{1}$, B. Dix ${ }^{1}$, R. Sinreich ${ }^{1}$, and R. Volkamer ${ }^{1,2}$ \\ ${ }^{1}$ Department of Chemistry and Biochemistry, University of Colorado, Boulder, CO, USA \\ ${ }^{2}$ CIRES - Cooperative Institute for Research in Environmental Sciences, Boulder, CO, USA
}

Received: 11 November 2010 - Published in Atmos. Meas. Tech. Discuss.: 17 January 2011

Revised: 21 October 2011 - Accepted: 24 October 2011 - Published: 10 November 2011

\begin{abstract}
We designed and assembled the University of Colorado Ground Multi AXis Differential Optical Absorption Spectroscopy (CU GMAX-DOAS) instrument to retrieve bromine oxide $(\mathrm{BrO})$, iodine oxide (IO), formaldehyde ( $\mathrm{HCHO})$, glyoxal (CHOCHO), nitrogen dioxide $\left(\mathrm{NO}_{2}\right)$ and the oxygen dimer $\left(\mathrm{O}_{4}\right)$ in the coastal atmosphere of the Gulf of Mexico. The detection sensitivity of DOAS measurements is proportional to the root mean square (RMS) of the residual spectrum that remains after all absorbers have been subtracted. Here we describe the CU GMAX-DOAS instrument and demonstrate that the hardware is capable of attaining RMS of $\sim 6 \times 10^{-6}$ from solar stray light noise tests using high photon count spectra (compatible within a factor of two with photon shot noise).

Laboratory tests revealed two critical instrument properties that, in practice, can limit the RMS: (1) detector non-linearity noise, $\mathrm{RMS}_{\mathrm{NLin}}$, and (2) temperature fluctuations that cause variations in optical resolution (full width at half the maximum, FWHM, of atomic emission lines) and give rise to optical resolution noise, $\mathrm{RMS}_{\mathrm{FWHM}}$. The nonlinearity of our detector is low $\left(\sim 10^{-2}\right)$ yet - unless actively controlled - is sufficiently large to create $\mathrm{RMS}_{\mathrm{NLin}}$ of up to $2 \times 10^{-4}$. The optical resolution is sensitive to temperature changes ( 0.03 detector pixels ${ }^{\circ} \mathrm{C}^{-1}$ at $\left.334 \mathrm{~nm}\right)$, and temperature variations of $0.1^{\circ} \mathrm{C}$ can cause $\mathrm{RMS}_{\mathrm{FWHM}}$ of $\sim 1 \times 10^{-4}$. Both factors were actively addressed in the design of the $\mathrm{CU}$ GMAX-DOAS instrument. With an integration time of $60 \mathrm{~s}$
\end{abstract}

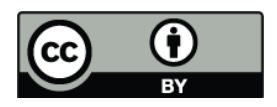

Correspondence to: R. Volkamer (rainer.volkamer@colorado.edu) the instrument can reach RMS noise of $3 \times 10^{-5}$, and typical RMS in field measurements ranged from $6 \times 10^{-5}$ to $1.4 \times 10^{-4}$.

The CU GMAX-DOAS was set up at a coastal site near Pensacola, Florida, where we detected $\mathrm{BrO}$, IO and CHO$\mathrm{CHO}$ in the marine boundary layer (MBL), with daytime average tropospheric vertical column densities (average of data above the detection limit), VCDs, of $\sim 2 \times 10^{13} \mathrm{molec} \mathrm{cm}^{-2}$, $8 \times 10^{12}$ molec cm $\mathrm{cm}^{-2}$ and $4 \times 10^{14}$ molec $\mathrm{cm}^{-2}$, respectively. $\mathrm{HCHO}$ and $\mathrm{NO}_{2}$ were also detected with typical MBL VCDs of $1 \times 10^{16}$ and $3 \times 10^{15}$ molec $\mathrm{cm}^{-2}$. These are the first measurements of $\mathrm{BrO}$, IO and CHOCHO over the Gulf of Mexico. The atmospheric implications of these observations for elevated mercury wet deposition rates in this area are briefly discussed. The CU GMAX-DOAS has great potential to investigate RMS-limited problems, like the abundance and variability of trace gases in the MBL and possibly the free troposphere (FT).

\section{Introduction}

Tropospheric halogen species, such as bromine oxide ( $\mathrm{BrO})$ and iodine oxide (IO), are of great interest to the emerging debate over the inter-relationships between air quality (Stutz et al., 2002) and climate change since they can destroy tropospheric ozone $\left(\mathrm{O}_{3}\right)$, which is both toxic and a greenhouse gas; can affect the partition of Nitrogen Oxides $\left(\mathrm{NO}_{\mathrm{x}}\right)$ and Hydrogen Oxides $\left(\mathrm{HO}_{\mathrm{x}}\right)$; may play a role in oxidizing gaseous elemental mercury $\left(\mathrm{GEM}, \mathrm{Hg}^{0}\right)$ to gaseous

Published by Copernicus Publications on behalf of the European Geosciences Union. 
oxidized mercury (GOM, $\mathrm{Hg}^{2+}$ ); and, for IO, can form new particles and/or add to the growth of pre-existing particles that may have adverse health effects and can have the potential to cool climate. The detection of halogen oxides, in particular $\mathrm{BrO}$, can pose experimental challenges. For instance, the detection of tropospheric $\mathrm{BrO}$ is very difficult due to its relatively low concentrations and its background abundance in the stratosphere. Whereas $\mathrm{BrO}$ radicals are typically about ten times as abundant as bromine atoms, both species are in a rapid photochemical steady state. $\mathrm{BrO}$ and bromine atoms are very reactive, and are rapidly lost by reaction with oxygenated volatile organic compounds (OVOCs), such as formaldehyde $(\mathrm{HCHO})$ and glyoxal $(\mathrm{CHOCHO}), \mathrm{HO}_{2}$ radicals, $\mathrm{NO}_{\mathrm{x}}$, or heterogeneous reactions, e.g., on surfaces, or in sampling lines (Atkinson et al., 2007). This leads to considerable analytical challenges with the sampling of these free radicals from the atmosphere by means of in-situ techniques and results in horizontal and vertical distributions of reactive bromine radicals that are very susceptible to gradients in the concentrations of OVOCs, $\mathrm{HO}_{2}$, and $\mathrm{NO}_{\mathrm{x}}$. The dependence on reactant gradients poses the question of how representative measurements near ground-level are over the depth of the marine boundary layer (MBL) and throughout the atmosphere. One way to investigate abundance of reactive halogen species is by detecting halogen oxide radicals directly in the open atmosphere using Differential Optical Absorption Spectroscopy (DOAS).

DOAS is a well-established technique (Platt and Perner, 1980; Platt, 1994; Platt and Stutz, 2008) used to identify trace gases by means of their individual differential (i.e., narrow band) absorption structures. In the past, the DOAS technique has been extensively used to measure halogen oxides (Hausmann and Platt, 1994; Hönninger and Platt, 2004; Wagner et al., 2007). Multi-AXis DOAS (MAX-DOAS) is a useful analytical technique that uses scattered sunlight collected at different viewing angles relative to the horizon to measure atmospheric trace gases directly in the open atmosphere (without the need to draw air through any sampling lines). The integrated concentrations of trace gases along each line of sight, termed the Slant Column Density (SCD), are derived using non-linear least-squares fitting of multiple trace gas reference spectra. Each spectrum is analyzed against a user-defined reference spectrum, which removes Fraunhofer absorption lines. In a typical DOAS measurement scenario the reference spectrum is recorded in the zenith viewing direction and at a low solar zenith angle (SZA) in order to minimize the contribution of the reference SCD from that of the analyzed spectrum. This produces a so called differential slant column density (dSCD). If the instrument is ground-based and the telescope is pointed close to the horizon, the increased path length through the surface layer of the atmosphere makes this technique particularly sensitive to trace gases within the boundary layer (Hönninger et al., 2002, 2004). This creates a distinct advantage in the use of MAX-DOAS to probe the marine/coastal boundary layer.
In the DOAS analysis, the residual structure of the fitting procedure is an indicator for the quality of the fit. This is usually expressed by the root mean square (RMS) of the residual's optical density. RMS of state-of-the-art hardware is typically $\sim 1 \times 10^{-4}$ or higher (Table 1 , also RMS $>10^{-4}$ for OMI instrument on EOS-Aura, K. Chance, personal communication, 2010; RMS $>10^{-4}$ for IO analysis of spectra recorded by the SCIAMACHY instrument aboard ENVISAT (Schoenhardt et al., 2008), A. Schoenhardt, personal communication, 2011), i.e., RMS typically does not improve further in accordance with photon-count statistics. The reasons for this have, to our knowledge, as yet not been elucidated. There are several parameters that influence the RMS of the DOAS analysis (Platt and Stutz, 2008) of solar stray light spectra. These can be divided into (1) hardware limitations (caused by non-linear detectors, instrument stray light, dark current, under sampling, instrument drifts, etc.), and (2) limitations in the representation of atmospheric state. The latter combine (2a) numerical limitations (during convolution of reference spectra, uncertainties in the wavelength pixel mapping, asymmetric or wavelength dependent instrument line shapes, analysis parameters) and (2b) limited knowledge about analysis inputs (e.g., spectroscopic parameters of literature cross-sections, wavelength calibration errors, unknown temperature dependencies, missing reference spectra, or imperfect representation of scattering processes (i.e., Ring)). In particular, the choice of the instrumentation used for the measurement can inherently determine the RMS when acquiring the spectra. Imaging spectrometers with longer focal lengths provide more steady projecting properties; larger size array detectors, and larger slit sizes provide for increased light throughput and thus lower photon shot noise, while smaller spectrometer/detector combinations tend to be more sensitive to temperature variations and optical drift. In part because larger focal length spectrometers and larger detector arrays are disproportionally more expensive, the advantages of small practical devices have recently been driving the development of MAX-DOAS hardware; one example of this is the Mini-MAX-DOAS hardware (Hönninger, 2002). MiniMAX-DOAS devices can be easily operated at remote sites, such as volcanoes (e.g., Bobrowski et al., 2003), with just battery power, or be set up quickly at any site, such as on vehicles (e.g., Ibrahim et al., 2010). However, currently available Mini-MAX-DOAS devices are often limited to RMS $\sim 10^{-3}$. In order to detect low concentrations of halogen oxide radicals more sophisticated devices are desirable. Stateof-the-art DOAS hardware provides for RMS on the order of $10^{-4}$. Recently, the first measurements with RMS values in the range of $8 \times 10^{-5}$ have been reported (Frieß et al., 2010) with a very stable instrument in the pristine Antarctic environment. Table 1 lists selected typical MAX-DOAS instruments and a few of their respective properties, including their RMS values. For a comprehensive look at the performance of the currently available MAX-DOAS instrumentation see Roscoe et al. (2010). The limitations on the attainable RMS 
values are one of the driving forces preventing the routine measurement of $\mathrm{BrO}$ by means of MAX-DOAS. A $\mathrm{BrO}$ dSCD on the order of $1 \times 10^{13}$ molec $\mathrm{cm}^{-2}$ corresponds to a differential optical density of $8 \times 10^{-5}$; however, even lower dSCD values would still be atmospherically relevant, i.e., for oxidizing mercury, and/or could affect the tropospheric ozone background. Using the calculation of path length based on the $\mathrm{O}_{4}$ dSCD described in Sinreich et al. (2010) and using a typical $\mathrm{O}_{4} \mathrm{dSCD}$ of $6 \times 10^{43} \mathrm{molec}^{2} \mathrm{~cm}^{-5}$ a BrO dSCD of $1 \times 10^{13} \mathrm{molec} \mathrm{cm}^{-2}$ relates to a mixing ratio of 2-3 ppt BrO. Only small concentrations of bromine atoms (corresponding to $<2 \mathrm{ppt}$ of $\mathrm{BrO}$ ) are sufficient to account for the observed levels of Gaseous Oxidized Mercury, GOM (Holmes et al., 2009). Consequently, low RMS measurements $\left(<10^{-4}\right)$ are a prerequisite to advancing our understanding of the bromine content of the atmosphere. In order to detect the low optical densities characteristic of $\mathrm{BrO}$ column abundances, improvements in the RMS values are a limiting factor.

Measurements by the Mercury Deposition Network (MDN) show that the southeastern United States is a region with elevated mercury wet deposition compared with the rest of the country. This cannot be solely attributed to mercury sources to the atmosphere, which are more abundant in other areas, such as the North Eastern United States industrial corridor, or natural sources that are more dispersed. This discrepancy suggests that the high deposition of mercury to the southeast might be due to the conversion of background atmospheric GEM to GOM, the latter of which is then readily wet-deposited. Whether this process would occur in the boundary layer, in the free troposphere (FT), and/or is a combination of both processes, remains unknown. The ATMOSpeclab at the University of Colorado at Boulder (CU) has developed and characterized a high sensitivity Ground-based MAX-DOAS instrument, the CU GMAX-DOAS. Here we describe the instrument, and present, to our knowledge, the first systematic study of the factors limiting RMS values as the photon shot noise (PSN) contribution is reduced to $\mathrm{RMS}_{\mathrm{PSN}}<10^{-4}$. We also present a first application of the CU GMAX-DOAS instrument measuring $\mathrm{BrO}, \mathrm{IO}, \mathrm{HCHO}$, $\mathrm{CHOCHO}, \mathrm{NO}_{2}$ and $\mathrm{O}_{4}$ at a coastal site near Pensacola, FL. This coastal site is in close proximity to a MDN station, and the Gulf of Mexico. The CU GMAX-DOAS was developed to investigate the potential role of halogens in mercury oxidation by measuring the relative abundances and vertical distributions of both $\mathrm{BrO}$ and $\mathrm{IO}$.

\section{Instrument description}

The CU GMAX-DOAS instrument collects spectra of scattered sunlight between 321.3 and $488.4 \mathrm{~nm}$ at different viewing angles, which are then analyzed in order to detect the presence of $\mathrm{BrO}, \mathrm{HCHO}, \mathrm{IO}, \mathrm{CHOCHO}, \mathrm{NO}_{2}$, and $\mathrm{O}_{4}$. The instrument consists of a telescope, located outdoors on an el-
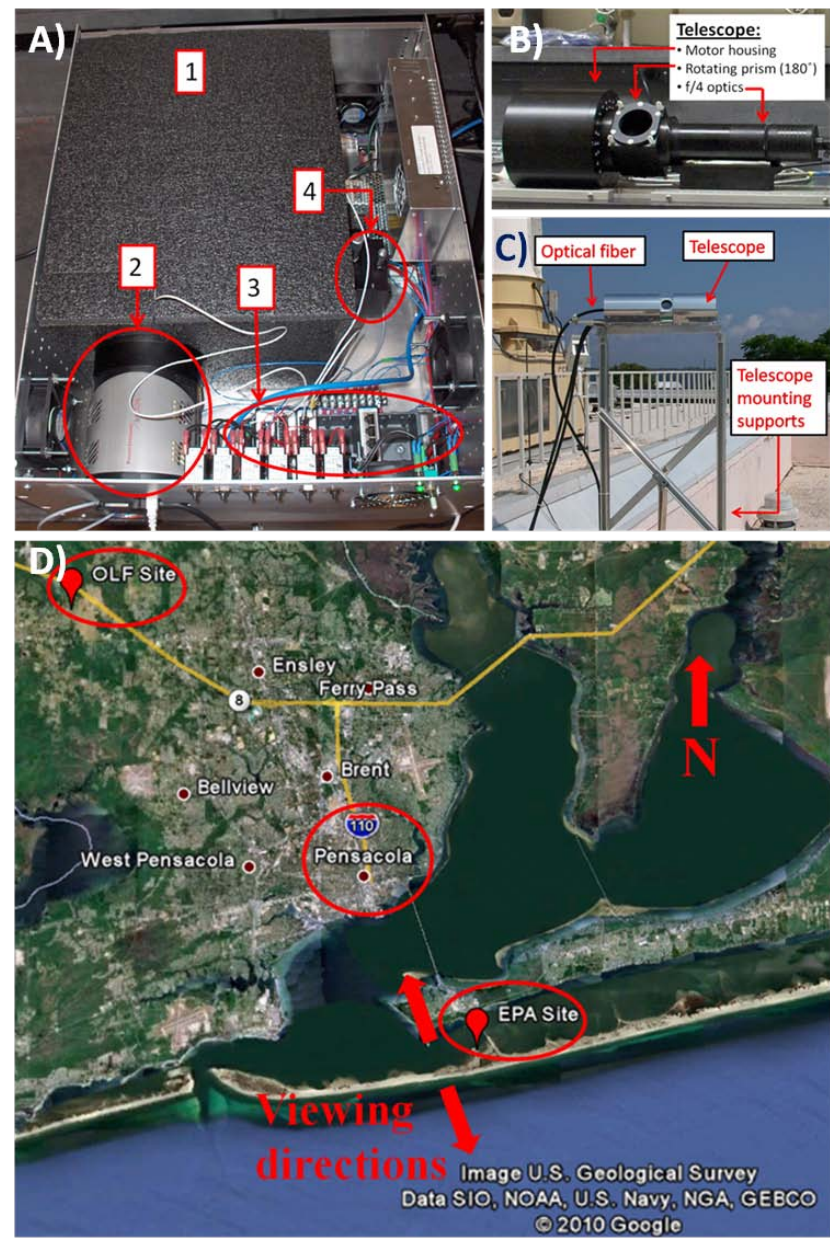

Fig. 1. (A) Instrument rack containing ACTON2356i spectrometer (1), PI PIXIS400B CCD detector (2), National Instruments Compact RIO with electronics modules (3), optical mounts to position fibers (4) and power supplies. (B) Telescope with housing of the MDrive34 stepper motor, rotating prism housing, and lens tube for f/4 optics. (C) Outdoor setup of telescope with solar shields to reduce heating of telescope. (D) Measurement sites: OLF located $\sim 20 \mathrm{~km}$ northwest of Pensacola, FL, and EPA located in Gulf Breeze, FL $\sim 10 \mathrm{~km}$ southeast of Pensacola.

evated platform to collect scattered sunlight, and the spectrometer/electronics rack, which is kept indoors in an airconditioned lab and has a two stage temperature control; it contains all of the electrical components needed to operate the instrument, as well as the spectrometer and detector. Figure 1 depicts the instrument components along with their placement and a map of the field sites at which it has been located. When comparing different MAX-DOAS hardware (Table 1), the effective slit area, which is the product of the height over which the detector is illuminated and slit width, is a measure of the instrument's ability to couple in-coming light onto the detector; in this regard, the CU GMAX-DOAS is one of the most light-efficient instruments. 
Table 1. Summary of performance capabilities and features of some of the currently reported MAX-DOAS instruments. The notation " $\mathrm{n} . \mathrm{a} . "$ signifies information that was not available. The RMS values reported are from typical DOAS evaluation windows ranging from $15-40 \mathrm{~nm}$, with the exception of the Pandora Goddard Space Flight Center reference which uses a rather wide window of $130 \mathrm{~nm}$.

\begin{tabular}{|c|c|c|c|c|c|c|c|c|c|c|}
\hline Reference & Location & Spectrometer & $\begin{array}{l}\text { Slit } \\
\text { height/width } \\
{\left[\mathrm{mm} \mu \mathrm{m}^{-1}\right]}\end{array}$ & $\begin{array}{l}\text { Effective } \\
\text { slit area } \\
{\left[\mathrm{mm}^{2}\right]}\end{array}$ & Detector make & $\begin{array}{l}\text { Detector } \\
\text { height } \\
{[\mathrm{mm}]}\end{array}$ & $\begin{array}{l}\text { Optical } \\
\text { resolution } \\
{[\mathrm{nm}]}\end{array}$ & $\begin{array}{l}\text { Covered } \\
\text { wavelength } \\
\text { range }[\mathrm{nm}]\end{array}$ & $\begin{array}{l}\text { Temperature } \\
\text { stability }\left[{ }^{\circ} \mathrm{C}\right]\end{array}$ & $\begin{array}{l}\text { Typical } \\
\text { RMS }\end{array}$ \\
\hline $\begin{array}{l}\text { CU GMAX- } \\
\text { DOAS }^{1}\end{array}$ & $\begin{array}{l}\text { Pensacola, } \\
\text { Florida, USA }\end{array}$ & Acton SP2356i & $>5.6 / 110$ & 0.6 & $\begin{array}{l}\text { 2-dimensional } \\
\text { CCD detector } \\
\text { (PIXIS 400B) }\end{array}$ & 8 & 0.77 & $322-488$ & \pm 0.06 & $\begin{array}{l}6 \times 10^{-5}- \\
1.4 \times 10^{-4}\end{array}$ \\
\hline $\begin{array}{l}\text { Mini-MAX- } \\
\text { DOAS }^{2}\end{array}$ & $\begin{array}{l}\text { e.g., } \\
\text { New England, } \\
\text { USA/ polluted }\end{array}$ & $\begin{array}{l}\text { Ocean Optics } \\
\text { USB2000 }\end{array}$ & $0.8 / 50$ & 0.04 & $\begin{array}{l}\text { 1-dimensional } \\
\text { CCD detector } \\
\text { (Sony ILX511) }\end{array}$ & 0.014 & 0.7 & $\begin{array}{l}290-420, \\
430-460\end{array}$ & \pm 0.2 & $8 \times 10^{-4}$ \\
\hline $\begin{array}{l}\text { Schwampel IUP } \\
\text { Heidelberg }^{2}\end{array}$ & $\begin{array}{l}\text { Mexico City/ } \\
\text { polluted }\end{array}$ & Acton 300 & $10 / 150$ & $\begin{array}{l}0.12 \text { (per } \\
\text { viewing } \\
\text { direction) }\end{array}$ & $\begin{array}{l}\text { 2-dimensional } \\
\text { CCD detector (An- } \\
\text { dor DV420-OE) }\end{array}$ & 6.7 & 0.7 & $325-460$ & \pm 0.1 & $2-4 \times 10^{-4}$ \\
\hline $\begin{array}{l}\text { Antarctica IUP } \\
\text { Heidelberg }\end{array}$ & Antarcica/ pristine & $\begin{array}{l}\text { n. a., Yobin } \\
\text { Yvon grating }\end{array}$ & $1.7 / 120$ & 0.16 & $\begin{array}{l}\text { Photodiode } \\
\text { array (Hamamatsu } \\
\text { ST3904-1024) }\end{array}$ & 2.5 & 0.5 & $400-650$ & n.a. & $8.2 \times 10^{-5}$ \\
\hline $\begin{array}{l}\text { Pandora Goddard } \\
\text { Space Flight } \\
\text { Center }^{4}\end{array}$ & $\begin{array}{l}\text { Thessaloniki, } \\
\text { Greece, and } \\
\text { Greenbelt, } \\
\text { Maryland, USA }\end{array}$ & $\begin{array}{l}\text { based on } \\
\text { an Avantes } \\
\text { spectrometer }\end{array}$ & n.a./50 & 0.02 & $\begin{array}{l}\text { 1-dimensional } \\
\text { Hamamatsu } \\
\text { CMOS }\end{array}$ & 0.025 & $0.42-0.52$ & $265-500$ & \pm 1 & $<5 \times 10^{-3}$ \\
\hline $\begin{array}{l}\text { MFDOAS } \\
\text { Washington State } \\
\text { University }{ }^{4}\end{array}$ & $\begin{array}{l}\text { Greenbelt, } \\
\text { Maryland. USA }\end{array}$ & Acton SP2356 & n.a./100 & 0.54 & $\begin{array}{l}\text { 2-dimensional } \\
\text { CCD } \\
\text { (PIXIS:2KBUV) }\end{array}$ & 6.9 & 0.83 & $282-498$ & \pm 2 & $<1 \times 10^{-3}$ \\
\hline $\begin{array}{l}\text { Frontier } \\
\text { Research } \\
\text { Center for Global } \\
\text { Change, Japan }\end{array}$ & $\begin{array}{l}\text { Tsukuba, Japan/ } \\
\text { polluted }\end{array}$ & $\begin{array}{l}\text { miniaturized } \\
\text { UV/visible } \\
\text { spectrometer } \\
\text { (B\&W TEK } \\
\text { Inc., BTC111) }\end{array}$ & n.a./10 & 0.007 & $\begin{array}{l}\text { 1-dimensional } \\
\text { CCD } \\
\text { (ILX511, Sony) }\end{array}$ & 0.014 & $0.4-0.55$ & $280-560$ & n.a. & $\begin{array}{l}0.7- \\
1.1 \times 10^{-3}\end{array}$ \\
\hline $\begin{array}{l}\text { Belgian } \\
\text { Institute for } \\
\text { Space } \\
\text { Aeronomy }\end{array}$ & La Reunion & $\begin{array}{l}\text { Acton } \\
\text { SpectraPro } 275\end{array}$ & n.a./n.a. & n. a. & $\begin{array}{l}\text { 2-dimensional } \\
\text { CCD (NTE/CCD- } \\
\text { 400EB) }\end{array}$ & 8 & 0.75 & $300-450 \mathrm{~nm}$ & n.a. & $\begin{array}{l}\text { about } \\
3.5 \times 10^{-4}\end{array}$ \\
\hline IUP Bremen ${ }^{7}$ & $\begin{array}{l}\text { Ny Alesund, } \\
\text { Norway/ pristine }\end{array}$ & Oriel MS 257 & n.a./n.a. & n.a. & $\begin{array}{l}\text { 2-dimensional } \\
\text { CCD of the Andor } \\
\text { DV 440-BU type }\end{array}$ & 6.9 & 0.5 & $325-413 \mathrm{~nm}$ & \pm 0.1 & $\begin{array}{l}\text { about } \\
1 \times 10^{-4}\end{array}$ \\
\hline
\end{tabular}

1 This work; ${ }^{2}$ Hönninger, 2002; Sinreich, 2008; ${ }^{3}$ Frieß et al., 2004, 2010; ${ }^{4}$ Herman et al., 2009; ${ }^{5}$ Irie et al., 2008, 2009; 6 Theys et al., 2007; Vigouroux et al., 2009;

7 Wittrock et al., 2004; Heckel et al., 2005

\subsection{Telescope}

The telescope is designed for high light throughput and very low dispersion (cone angle of $0.3^{\circ}$ ). It is comprised of a motor with housing, a rotating prism with housing mounted to the motor axis, and a lens tube. The outer components are made from black anodized aluminum and are protected by a thin polished aluminum shield in order to reduce solar heating of the telescope (Fig. 1b, c). The rotating prism housing is driven by an Intelligent Motion Systems Inc. MDrive34 Plus motor with internal encoder that is located in the motor housing. The shaft of the motor is attached directly to a custom-made rotating assembly that holds a $5 \mathrm{~cm} \times 5 \mathrm{~cm}$ right angle fused silica prism; and an O-ring sealed sapphire window (optical diameter $50.8 \mathrm{~mm}, 1 \mathrm{~mm}$ thick). During measurement, light is collected via the sapphire window on the main face of the prism housing and enters the prism where it is directed onto an $\mathrm{f} / 45 \mathrm{~cm}$ lens mounted in the opposite direction from the motor onto the prism holder. Both junctions of the prism housing contain two separate O-ring seals to prevent water from entering the prism hous- ing. Additionally, both the prism housing and the lens tube contain small bags filled with silica gel bead drying agent to actively dry the air around the optics and prevent possible condensation on the optical components. The entire prism housing can be rotated 360 degree by changing the motor axis; this rotation defines the elevation angle over which the prism collects light from the atmosphere. The telescope and electronics rack are coupled by optical fibers and electronics cables. The light is focused via the lens tube onto a CeramOptics $10 \mathrm{~m} \times 1.7 \mathrm{~mm}$ silica monofiber that is connected to an OceanOptics $5 \mathrm{~m}$ fiber bundle consisting of $27 \times 200 \mu \mathrm{m}$ fibers. This fiber bundle is configured in a circular arrangement at the fiber junction and then forms a linear array at the spectrometer end. This end of the fiber bundle is directed onto the slit of the spectrometer, which is set at a width of $110 \mu \mathrm{m}$. Two filters; a BG3 and a BG38, were placed inside the lens tube to reduce the amount of visible and near infra red light that could contribute to stray light in the spectrometer, as well as to balance out the light intensity differences between the UV and visible wavelength regions across the detector. The chosen optics maximizes the 
amount of light collected, thus improving the signal-to-noise ratio and time resolution of measurements.

\subsection{Spectrometer, CCD detector and electronics rack}

The spectrometer, detector and controlling electronics are housed in a standard 19" aluminum instrument rack with modifications to the floor and the lid for added stability. The spectrometer is a Princeton Instruments Acton SP2356i Imaging Czerny-Turner spectrometer with a PIXIS 400 back illuminated CCD detector equipped with UV fluorescence coating. The spectrometer was equipped with a custom 500 grooves $\mathrm{mm}^{-1}$ grating (Richardson, $300 \mathrm{~nm}$ blaze angle). This grating gives simultaneous coverage from 321.3$488.4 \mathrm{~nm}$, or a range of $167.1 \mathrm{~nm}$. The quadratic dispersion equation for the wavelength setting here is

$\lambda=321.27+0.125(x)-2.656 \times 10^{-7}\left(x^{2}\right)$

where $x$ denotes the pixel number, and the linearly approximated dispersion is $0.125 \mathrm{~nm}_{\text {pixel }}{ }^{-1}$. The $110 \mu \mathrm{m}$ wide slit width corresponds to a linearly approximated spectral resolution of $\sim 0.68 \mathrm{~nm}$ FWHM. This has been experimentally determined by means of fitting a Gaussian function to a mercury atomic line spectrum of the $404.66 \mathrm{~nm}$ line to be $\sim 0.74 \mathrm{~nm}$. The PIXIS 400B CCD is a UV-optimized twodimensional array detector with $400 \times 1340$ pixels. Our software sets the gain of the readout register ADC during CCD initialization. This CCD gain is typically set to the lowest gain value (high capacity mode), which corresponds to a photon-into-count conversion factor of 16 ; increasing this gain makes the CCD more sensitive but also reduces the pixel well capacity, and thus has the primary effect to shorten integration times to reach a certain saturation level. Notably, the use of the CCD in high capacity mode maximizes the useful well capacity, and minimizes the attainable RMS noise from a single acquisition. For CCD readout, two rows are binned to reduce data volume; we use a readout rate of $2 \mathrm{MHz}$ (readout noise $<16$ electrons rms), corresponding to a readout time of $134 \mathrm{~ms}$. The CCD is cooled to $-70^{\circ} \mathrm{C}$ to reduce dark current. The data acquisition software reads a configuration file that specifies a lower and upper row number for illuminated CCD rows (ROI or "region of interest"), and similarly specifies row numbers for "dark" areas of the CCD chip; the latter are used to characterize background in terms of electronic offset, dark current, background and spectrometer stray light. The offset and dark current correction of measured spectra is similar to Wagner et al. (2004). The spectrometer stray light after these corrections was determined to be below $0.1 \%$ in our setup. It was verified in laboratory tests that under these operating conditions the detector read-out noise and dark current noise are negligible, and RMS noise essentially follows photon counting statistics. The software saves both a background corrected 1-D spectrum, and a full 2-D image. For instrument control, a National Instruments CompactRIO electronics chassis, capacity of up to eight modules, was interfaced with our custom built LabVIEW data acquisition code to provide a framework for tracking and controlling numerous instrument parameters, including voltage monitoring, temperature read-back, solid state relay control for software proportional-integral-derivative (PID) temperature stabilization, and fully integrated communications with the telescope motor, spectrometer and CCD detector.

Additional parameters accessible through the software include: selecting and controlling the CCD target saturation level (which represents the ratio of the counts derived from digitizing a spectrum divided by the full dynamic range of the 16-bit ADC used to digitize the spectrum) within a selectable wavelength range, setting upper and lower bounds in which the target saturation level is allowed to vary, automatic determination of the proper integration time to adjust the saturation level within these bounds, automatic rejection of saturated spectra prior to the data storage, and fine tuning the PID parameters used for temperature stabilization of the electronics rack housing as well as the spectrometer. During the software determination of the integration time based on the user defined saturation level inputs, the maximum value from a single pixel from a specified column range on the CCD is used. This allows us to maintain a target saturation level within a specific wavelength range, even if the relative distribution of intensity across the CCD chip is changing its spectral shape due to changing light conditions, allowing us to optimize a measurement to target a particular trace gas (wavelength range) while not losing information about trace gases measured in a different wavelength range.

Temperature stability is a key component to consider when designing and building MAX-DOAS instrumentation because even small fluctuations can result in changes in instrument properties, such as line shape and dispersion of the spectrometer, and dark current noise in the detector. In order to maintain a stable temperature, the spectrometer was fitted with insulating foam and a small heating foil controlled by a PID loop in the LabVIEW software. Two temperature sensors (Omega PT100 high precision RTDs, accuracy $1 / 10 \mathrm{DIN}$, read out noise: $0.003{ }^{\circ} \mathrm{C}$ peak to peak) were placed on the instrument, one on the bottom near the heating foil to provide feedback for the PID loop, and one on the top of the instrument to provide information about the temperature gradient over the spectrometer chassis. Additionally, the rack was fitted with an external housing that provided insulation between the inside of the rack and the ambient air. The top of this housing was equipped with 6 single-stage peltier cooling units, used to stabilize the temperature inside the rack. The peltiers are controlled by a series of heavy duty solid state relays that are triggered by a signal received from a PID controlled solid state relay as part of the NI cRIO. With these measures in place, during normal operation, the sensor closest to the heating foil was stable within $0.005^{\circ} \mathrm{C}$, while the sensor atop the instrument varied by $0.06^{\circ} \mathrm{C}$ over an $8 \mathrm{~h}$ period. During this time the rack temperature was stable to within $\sim 0.8^{\circ} \mathrm{C}$ while ambient temperature varied by more 
than $6{ }^{\circ} \mathrm{C}$. While the detector and fiber mounting hardware are contained within the secondary temperature stabilization unit, they are not necessarily in thermal equilibrium with the spectrometer, and their temperature is controlled to within the range of temperature variations as measured by the second temperature sensor on the spectrometer, and that inside the instrument rack.

\section{Laboratory characterization of the $\mathrm{CU}$ GMAX-DOAS}

The following section describes laboratory experiments to assess spectral drift in the wavelength-pixel mapping, changes in the slit function as a function of temperature, optical resolution across the detector, detector non-linearity, and signal-to-noise levels.

\subsection{Temperature sensitivity tests}

To test the temperature sensitivity of the instrument, atomic line spectra from a PenRay Mercury-Argon lamp were recorded at five different temperatures ranging from $27^{\circ} \mathrm{C}$ to $40^{\circ} \mathrm{C}$. The lines at $334.15 \mathrm{~nm}$ ( $\sim$ pixel 104$), 404.66 \mathrm{~nm}$ ( $\sim$ pixel 667 ), and $435.84 \mathrm{~nm}$ ( $\sim$ pixel 918) were chosen to characterize the shifts (changes in the line center position) and changes in line shape over this temperature range. These three lines were chosen to characterize the spectral projection in the center position of the CCD detector (404 nm line) and off-center of the CCD detector. Tests were performed by first allowing the spectrometer to stabilize for $\sim 1 \mathrm{~h}$ at the desired temperature and then recording the line spectra using the Hg-Ar lamp. The spectra were then analyzed by fitting a Gaussian line shape profile to each of the atomic lines (IgorPro, Wavemetrics). The center position and line width parameters derived from the fitting procedure were used to determine both shifts and line broadening as a function of temperature (Fig. 2). Shift is defined as the difference in the center position of the fit for each temperature relative to the position at $30^{\circ} \mathrm{C}$; line width broadening is the difference in the FWHM derived from the fit as compared to a reference FWHM at $30^{\circ} \mathrm{C}$. Drift in the wavelength pixel mapping (shift) of this instrument is $\sim 0.1$ pixel ${ }^{\circ} \mathrm{C}^{-1}$. The dependence of shift on temperature is found to be well-represented by a linear regression (Fig. 2d). The linear regression coefficients were determined to be $0.08 \pm 0.01$ pixels ${ }^{\circ} \mathrm{C}^{-1}$, for the three slopes in Fig. 2d, with $R^{2}$ values of 0.95 for the three lines.

\subsection{Effect of line-shape broadening on RMS}

Table 2 illustrates the effect of line shape broadening on the RMS values obtainable during a DOAS fitting procedure. The effect of line shape broadening was determined by convoluting a literature Fraunhofer spectrum (Kurucz et al., 1984) with Gaussian shaped calculated line-shape functions that differed in FWHM by the number of pixels as given
Table 2. Calculated RMS dependence on symmetric line shape broadening (Gaussian line shape).

\begin{tabular}{llll}
\hline & Range & $430-470 \mathrm{~nm}$ & $330-370 \mathrm{~nm}$ \\
\hline Difference (pixels) & Difference $(\mathrm{nm})$ & RMS $_{\mathrm{FWHM}}$ & $\mathrm{RMS}_{\mathrm{FWHM}}$ \\
\hline 1 & $1.24 \times 10^{-1}$ & $1.50 \times 10^{-2}$ & $2.5 \times 10^{-2}$ \\
0.1 & $1.24 \times 10^{-2}$ & $1.81 \times 10^{-3}$ & $3.07 \times 10^{-3}$ \\
0.01 & $1.24 \times 10^{-3}$ & $1.84 \times 10^{-4}$ & $3.13 \times 10^{-4}$ \\
0.001 & $1.24 \times 10^{-4}$ & $1.84 \times 10^{-5}$ & $3.14 \times 10^{-5}$ \\
0.0001 & $1.24 \times 10^{-5}$ & $1.83 \times 10^{-6}$ & $3.12 \times 10^{-6}$ \\
0.00001 & $1.24 \times 10^{-6}$ & $1.40 \times 10^{-7}$ & $2.38 \times 10^{-7}$ \\
\hline
\end{tabular}

in Table 2. The convoluted Fraunhofer spectrum was then divided by a Fraunhofer spectrum convoluted using a reference line shape width (here $0.79 \mathrm{~nm}$ ). These tests were conducted in two wavelength ranges as illustrated in Table 2. Since the slit temperature is somewhat buffered by the heat capacity of the spectrometer, its stability is expected to be nearer to the stability of the instrument $\left(\sim 0.06^{\circ} \mathrm{C}\right)$ than that of the rack $\left(0.8^{\circ} \mathrm{C}\right.$ peak to peak variations $)$, but it is most likely somewhere between these values. The rack temperature variations showed oscillations with a period of $\sim 30$ min that followed variations in the room temperature of $\sim 7^{\circ} \mathrm{C}$, and appeared to be driven by the period at which the room air conditioning (AC) would turn ON/OFF; our second stage temperature control reduced the amplitude of room temperature variations by a factor of $\sim 10$ inside the rack. We estimate the instability of our slit temperature, $\Delta T_{\text {slit }}$, as the 1-sigma temperature variability of $10 \mathrm{~min}$ averaged rack temperature variations (i.e., assuming a $10 \mathrm{~min}$ time constant of the slit to respond to rack temperature changes). Over the course of a day $\Delta T_{\text {slit }}$ was $0.054^{\circ} \mathrm{C}$ (1-sigma) for periods when the $\mathrm{AC}$ was $\mathrm{OFF}$ and $0.21^{\circ} \mathrm{C}$ (1-sigma) when the $\mathrm{AC}$ unit was ON. Based on Table 2 we expect the attainable $\mathrm{RMS}_{\mathrm{FWHM}}$ of our instrument to range from $<1 \times 10^{-5}$ to $5 \times 10^{-5}\left(0.054^{\circ} \mathrm{C}\right.$, representative of $80 \%$ of the data) and $5 \times 10^{-5}$ to $1.8 \times 10^{-4}$ $\left(0.21^{\circ} \mathrm{C}, 20 \%\right.$ of the data), with larger numbers expected in the UV region of the spectrum.

\subsection{Shift characterization}

The numerical uncertainty with which different reference spectra can be mapped onto a common wavelength pixel relation during the non-linear least square analysis of DOAS spectra depends on the absolute accuracy of the wavelength calibration of literature cross-sections. In order to assess the effect of shift error on the RMS, a solar spectrum was copied and one of the copies was systematically shifted by the amounts shown in Table 3 and then the spectra were divided. The solar spectrum used was created by co-adding a series of spectra collected at an elevation angle of $80^{\circ}$. Five hundred and sixty spectra, each with an integration time of $5 \mathrm{~s}$, were co-added leading to a final spectrum with a total 

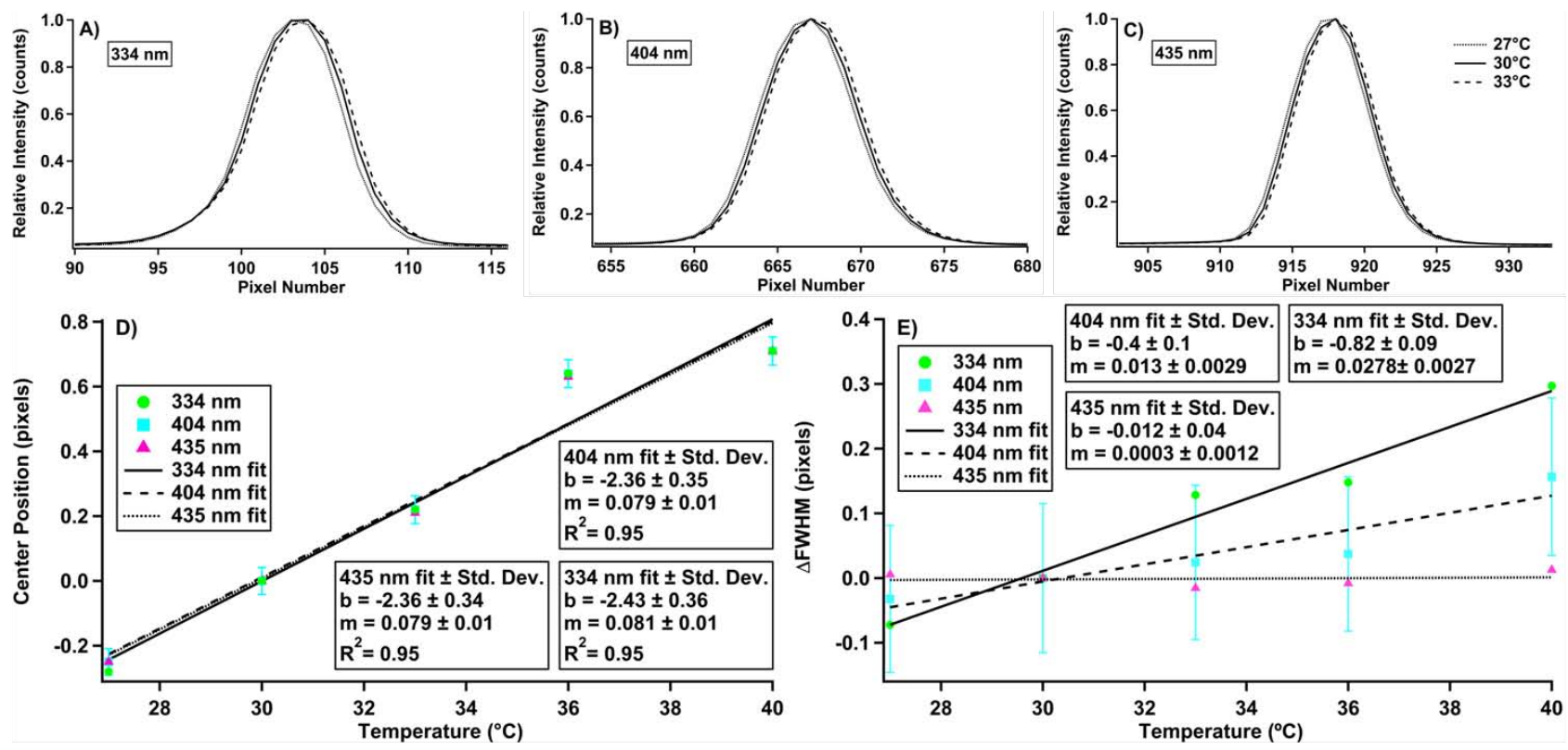

Fig. 2. Characterization of the spectrometer/detector system with respect to temperature changes. (A-C) Spectral line shape as a function of temperature for $334 \mathrm{~nm}, 404 \mathrm{~nm}$, and $435 \mathrm{~nm}$, atomic emission lines of an Hg-Ar lamp. (D) Spectral shift of atomic lines as a function of temperature. (E) Difference in the full width at half the maximum of the line shapes as a function of temperature.

Table 3. Calculated RMS noise as a function of shift imprecision for two wavelength ranges.

\begin{tabular}{lccc}
\hline & Range & $430-470 \mathrm{~nm}$ & $330-370 \mathrm{~nm}$ \\
\hline Shift (pixel) & Shift (nm) & RMS & RMS \\
\hline 0.1 & $1.24 \times 10^{-2}$ & $1.69 \times 10^{-3}$ & $2.49 \times 10^{-3}$ \\
0.01 & $1.24 \times 10^{-3}$ & $1.69 \times 10^{-4}$ & $2.49 \times 10^{-4}$ \\
0.001 & $1.24 \times 10^{-4}$ & $1.69 \times 10^{-5}$ & $2.49 \times 10^{-5}$ \\
0.0001 & $1.24 \times 10^{-5}$ & $1.69 \times 10^{-6}$ & $2.49 \times 10^{-6}$ \\
0.00001 & $1.24 \times 10^{-6}$ & $1.69 \times 10^{-7}$ & $2.49 \times 10^{-7}$ \\
\hline
\end{tabular}

integration time approaching $50 \mathrm{~min}$. This many spectra were used in order to obtain a high photon count in the final spectrum for this test. The shift error effect on RMS was determined to be independent of number of photons of the spectrum. The wavelength regions between $430-470 \mathrm{~nm}$ and $330-370 \mathrm{~nm}$ were used, which corresponds to 323 and 320 pixels, respectively. Table 3 shows that in order to achieve an RMS on the order of $1 \times 10^{-4}$ and $1 \times 10^{-5}$ the shift needs to be determined with an accuracy of $\sim 6 \times 10^{-3}$ and $\sim 6 \times 10^{-4}$ pixels for the $430-470 \mathrm{~nm}$ range, and $\sim 4 \times 10^{-3}$ and $\sim 4 \times 10^{-4}$ pixels in the $330-370 \mathrm{~nm}$ range.

Notably, the uncertainty in the wavelength calibration of literature cross-sections can become limiting if such low RMS is to be realized, in particular when measuring in the presence of abundant trace gases, for instance $\mathrm{NO}_{2}$ in this study. While the DOAS non-linear least-squares fit allows for a shift in the literature cross-sections relative to the wavelength pixel mapping of the instrument, any inherent inaccuracies in the original wavelength calibration during recording of the literature cross-sections could potentially limit the achievable RMS (see Sect. 4.2).

\subsection{Detector non-linearity}

The non-linearity of the detector is a critical property with DOAS applications (Stutz and Platt, 2008). Detector nonlinearity is particularly important with solar stray light DOAS applications, since it distorts the apparent shape of Fraunhofer lines that are present in the solar spectrum and have to be eliminated accurately in order to make the much weaker atmospheric absorbers visible. Figure 3 presents a theoretical treatment of detector non-linearity for an example solar stray light spectrum recorded with our instrument (Fig. 3a). We simulate the distortion of Fraunhofer lines for a $1 \%$ non-linearity over $100 \%$ saturation, which is typical of state-of-the-art CCD detectors like the one used in this study. Copies of the spectrum were modified $\left(I_{\mathrm{mod}}\right)$ to reflect recording at $20 \%, 40 \%, 60 \%, 80 \%$ and $100 \%$ saturation, by multiplication with a wavelength dependent factor calcu-

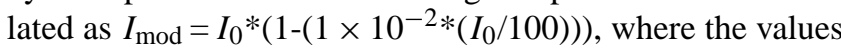
in $I_{0}$ vary between $1 \%$ and $100 \%$, thus reflecting a $0.1 \%$ intensity change for every $10 \%$ of detector saturation. The DOAS retrieval program, WinDOAS (Fayt and Roozendael, 2001), was used to process spectra from these and all subsequent tests. The software performs a non-linear least-squares 
fit by simultaneously adjusting the optical cross-sections of relevant atmospheric trace gases in the respective wavelength range to the measured spectra. To account for broad band effects (in particular caused by Rayleigh and Mie-scattering) a third degree polynomial was included. The fitting procedure is performed with the logarithm of the spectra (i.e., in optical density space). Additionally, the software can accommodate shifting the analyzed spectra in order to account for spectrometer drifts, which result in differences in the wavelength pixel mapping between the reference and the analyzed spectrum. In some cases a pre-logarithmic linear intensity offset was included to account for stray light. All of these parameters are adjustable via the software interface and can be optimized for different retrievals, such as the tests described here. Figure $3 \mathrm{~d}$ and e shows residual spectra from the DOAS analysis (two wavelength windows; $345-360 \mathrm{~nm}$ and $425-$ $440 \mathrm{~nm}$, and only including combinations of either a Ring cross-section (Chance and Spurr, 1997), a linear intensity offset, neither of these, or both) of simulated spectra with saturation level differences of $80 \%$ (100\% sample, $20 \%$ reference) and $20 \%$ (40\% sample, $20 \%$ reference). The RMS residual is $6 \times 10^{-5}$ and $1.5 \times 10^{-4}$ for $345-360 \mathrm{~nm}$ and $425-440 \mathrm{~nm}$, respectively. Illustrated in Fig. $3 \mathrm{~b}$ and c is the RMS residual structure from the $20 \%$ saturation level difference case, as well as a linear intensity offset fit and a Ring reference cross-section calculated from the reference spectrum. It is clear from the similarity of these spectra that the artifact of distorted Fraunhofer lines due to detector nonlinearity is strongly cross-correlated, and will modify the fit coefficient of either of these spectra leading to an artificial reduction in the $\mathrm{RMS}_{\mathrm{NLin}}$. Fitting of a Ring leads to about a factor of 4 reduction in $\mathrm{RMS}_{\mathrm{NLin}}$, yet systematic residual structures remain.

Figure 4 compares the RMS from these simulations (Fig. 4a, c) with the RMS from solar stray light spectra (Fig. 4b, d) that were recorded over a wide range of delta saturations. These tests were comprised of taking near zenith spectra at varying detector saturation levels and testing the effect of analyzing either a spectrum of the same saturation level or one of a different saturation level. For these tests, the integration times for the spectra varied due to the manipulation of the saturation level, but for all spectra the number of photons collected was kept near constant (within a few percent) at $10^{10}$ near the maximum. The wavelength windows used for the analysis of this data were also $345-360 \mathrm{~nm}$ and $425-440 \mathrm{~nm}$, but since different solar stray light spectra were used additional reference cross-sections needed to be included in the fit. In the UV window, the included crosssection references were: two $\mathrm{O}_{3}$ references (at different temperatures), a Ring spectrum, and an $\mathrm{NO}_{2}$ reference. In the visible window, the reference cross-sections were the same except only one $\mathrm{O}_{3}$ was used.
If two spectra from the same target saturation are compared the RMS is statistical, and the derived RMS $=4 \times 10^{-5}$ and $2 \times 10^{-5}$ for the $345-360 \mathrm{~nm}$ and the $425-440 \mathrm{~nm}$ ranges, respectively, compares well with the theoretical value of $3 \times 10^{-5}$ and $1.7 \times 10^{-5}$ based on photon counting statistics. However, RMS increases linearly as delta saturation increases, and the linear dependence of $\mathrm{RMS}_{\mathrm{NLin}}$ on delta saturation in the measured data indicates that the detector non-linearity is approximately constant over the full dynamic range of our CCD detector. By comparison of the slope with that from simulations at different detector non-linearities, our detector non-linearity is quantified as $1 \% \pm 0.3 \%$ for $100 \%$ delta saturation at the two wavelengths (reflecting a factor of 2 different saturation levels at $350 \mathrm{~nm}$ and $440 \mathrm{~nm}$ ). The manufacturer specified detector non-linearity is given as $<1 \%$ in the datasheet, in marginal agreement with our measured non-linearity. Fitting of an intensity offset gives slightly better $\mathrm{RMS}_{\mathrm{NLin}}$ than fitting of a Ring, yet represents an artificial improvement in RMS. Fitting of both Ring and intensity offset can create strong bias in the fit factors for both spectra. The systematic $\mathrm{RMS}_{\mathrm{NLin}}$ residual structures that remain can be on the order of $10^{-4}$ for large delta saturations in the two spectral ranges studied. At other wavelengths $\mathrm{RMS}_{\mathrm{NLin}}$ is expected to scale with the optical density of Fraunhofer lines.

The limitation in RMS is caused by the shape of Fraunhofer lines and depends on the saturation level at which spectra are recorded. The demonstrated increase in RMS cannot be explained by atmospheric absorbers, which are accounted for in the analysis procedure, and is a strong indication that non-linearities in the detector limit the way that Fraunhofer lines can be characterized with available stateof-the-art CCD detectors. However, Fig. 4 also demonstrates that the distortion of Fraunhofer lines from detector nonlinearity is not necessarily a problem that limits DOAS RMS. Only an inconsistent use of the detector causes a limitation, due to the inconsistent characterization of Fraunhofer lines, and gives rise to $\mathrm{RMS}_{\mathrm{NLin}}$ to limit the overall RMS. In order to reduce $\mathrm{RMS}_{\mathrm{NLin}}$ to $<5 \times 10^{-5}$ without the need to artificially reduce RMS by fitting an intensity offset or Ring spectrum, the saturation level of the detector cannot vary by more than $6 \%$ at $440 \mathrm{~nm}$, and not more than $16 \%$ at $350 \mathrm{~nm}$ (Fig. 4). The solution implemented in the ATMOSpeclab data acquisition LabVIEW code follows the approach described by Volkamer et al. (2009). In addition to a given target saturation level two additional variables are set, i.e., the upper and lower limit for the target saturation. These provide not-to-exceed bounds close to the target saturation during the acquisition of spectra, i.e., set here to within $5 \%$. This approach is implemented here in the first field deployment of the CU GMAX-DOAS instrument. 


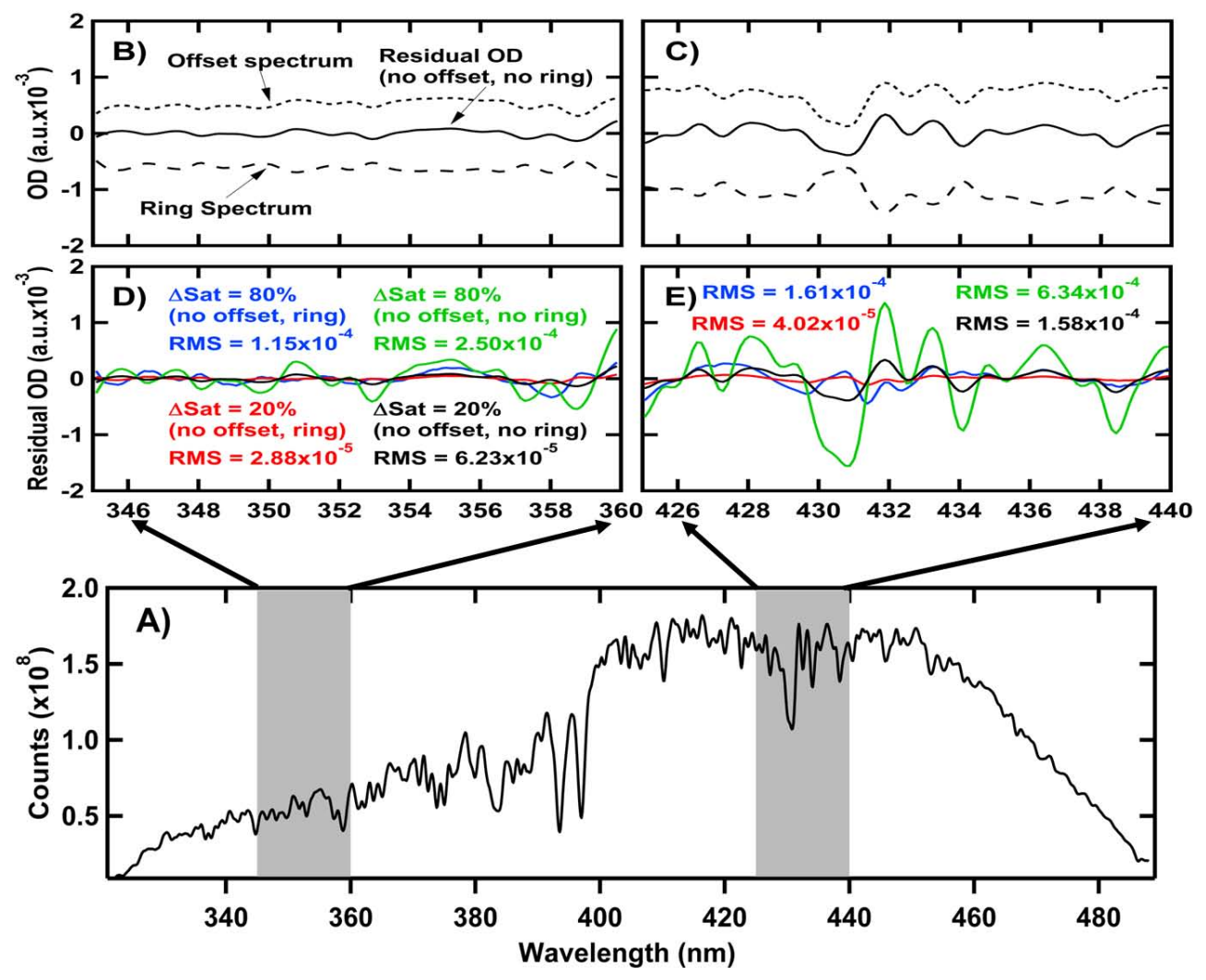

Fig. 3. Assessment of detector non-linearity through simulated spectra. Bottom panel (A) depicts an example spectrum with the wavelength intervals analyzed highlighted with the grey background. Top panel (B and $\mathbf{C}$ ) demonstrates the spectral cross-correlation between the residual structure due to nonlinearity (solid line, no Ring fit and no offset), the Ring fit (dashed line), and the linear intensity offset (dotted line). Middle panel (D and $\mathbf{E}$ ) shows the residual of the analyses for the two wavelength intervals for four different simulated scenarios. In (D) and (E), the blue and green lines represent data with a saturation level difference (sample - reference) of $80 \%$ and the blue line depicts the results including a Ring spectrum in the fitting window and the green line is the results without including the Ring spectrum. The red and black lines represent the corresponding spectra with a saturation level difference of $20 \%$, where the red line is the fit including the Ring spectrum and the black line does not include the Ring.

\subsection{Signal-to-noise tests}

The signal-to-noise as a function of the number of photons collected was characterized using our LabVIEW-based processing tool called the Intelligent Averaging Module (IAM) ${ }^{1}$. Scattered sunlight spectra were collected in two modes of operation: (mode1) during normal measurements, where a set of eleven different elevation angles each with an integration time of $60 \mathrm{~s}$ were scanned during one measurement sequence, and (mode2) during a viewing routine (labelled as field tests) that measured only two elevation angles; $80^{\circ}$ (which served as the reference) and $25^{\circ}$, and twenty spectra were taken sequentially at both elevation angles all with $5 \mathrm{~s}$ integration times. For all tests, when analyzing spectra in different wavelength regions a line function from each region

${ }^{1}$ Intelligent Averaging Module (IAM): Part of the custom built LabVIEW software that allows complex handling and manipulation of the spectra in order to optimize our analysis. This is a powerful tool that allows the user full control over how the data is handled. is chosen to convolute the cross-section reference spectra to help account for differences in line shape across the CCD.

Unless otherwise noted, the WinDOAS settings for all tests included two wavelength regions, between $340-359 \mathrm{~nm}$ where $\mathrm{BrO}$ is measured and $415-438 \mathrm{~nm}$ where IO is measured. The Ring reference was calculated using the DOASIS software (Kraus, 2006) from a spectrum measured with our instrument. In the analysis of the set of data collected during normal operations, a routine was used such that each spectrum was analyzed by a close in time reference spectrum; this helped to accurately characterize and eliminate stratospheric absorbers. A new Ring spectrum was created from each new reference and updated in the analysis. For the field tests, IAM was used in two different ways to process these spectra. The first use included adding a specified number of spectra (in this case 4, 16, and 64 spectra) for the viewing angles and then analyzing the resulting spectrum. For the processing of these spectra, the reference spectrum was created by adding 20 sequential individual $80^{\circ}$ spectra (this summed spectrum 

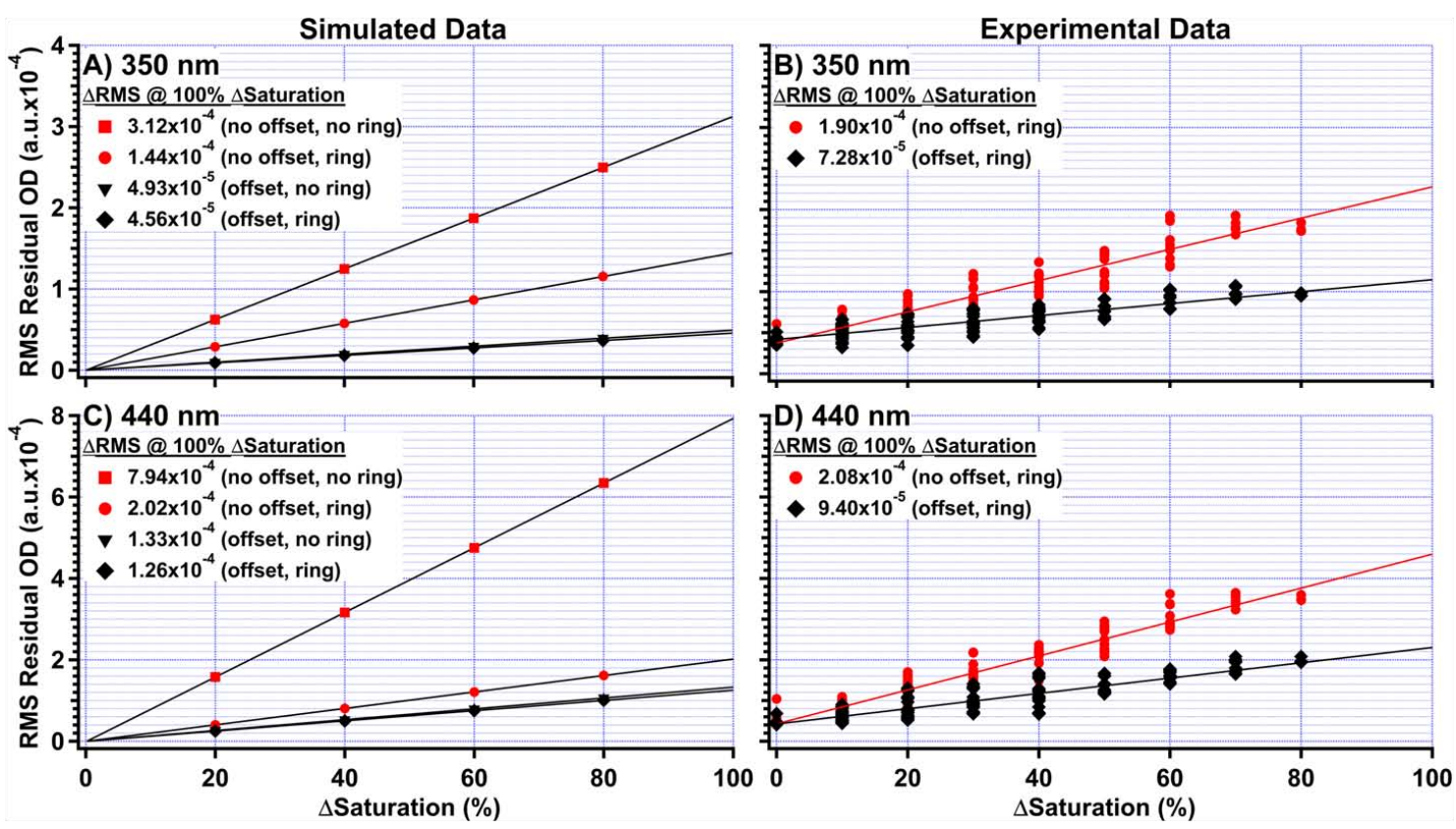

Fig. 4. Correlation of simulated (A and $\mathbf{C})$ and experimental (B and $\mathbf{D})$ data testing the non-linearity of our CCD detector at two different wavelengths: $350 \mathrm{~nm}(\mathbf{A}$ and $\mathbf{B})$ and $440 \mathrm{~nm}(\mathbf{C}$ and $\mathbf{D})$. Coefficients for linear regressions fit to the data were extrapolated to determine the RMS value corresponding to $100 \%$ of the dynamic range of the detector, and these values are listed for the different fit scenarios in each of the panels.

was then used to calculate the Ring reference spectrum). In the second method, ratios were created using two sequential spectra of the same viewing angle, and these ratios were then added together to form the final spectrum that was used in the analysis. In this method, the final spectra were made of the sum of 500 and 1000 ratio spectra. For the analysis of these spectra, no reference was used, the Ring was the same that was used for the first method, and no offset was included. A summary of the cross-section used in each of these analyses can be found in Table 4 .

Additionally, tests were done with a tungsten lamp in order to assess the instrument's performance without the influence of Fraunhofer lines. In these tests, sequential spectra of the same photon count, corrected for dark current and electronic offset, were divided in WinDOAS without including an intensity offset or any other cross-section references and not allowing the spectra to shift. This analysis was performed around the maximum of the tungsten lamp (440-465 nm). The division of two spectra that contained $\sim 3 \times 10^{11}$ photons each allowed us to achieve an RMS of $3 \times 10^{-6}$, which compares very well to RMSPSN $=2.5 \times 10^{-6}$ based on photon counting statistics.

The results from these tests along with the theoretical noise, based on photon counting statistics, are summarized in Fig. 5. Theoretical noise based on photon counting statistics was calculated according to the equation

$\mathrm{RMS}=\left(\left(1 / N_{\mathrm{ms}}\right)^{2}+\left(1 / N_{\mathrm{rs}}\right)^{2}\right)^{1 / 2}$ where $N_{\mathrm{ms}}$ is the number of photons in the measured spectrum and $N_{\mathrm{rs}}$ is the number of photons in the reference spectrum. Also included in Fig. 5 are results from field measurements of the $155^{\circ}$ and $178.5^{\circ}$ elevation angles (solid green circles and open green circles, respectively), which typically were in the $6 \times 10^{-5}-1.4 \times 10^{-4}$ range (red whiskers give statistics of green points) at high photon count. Increasing the numbers of solar stray light photons, the lowest RMS values achieved by the noise tests were $\sim 1 \times 10^{-5}$ and $\sim 6 \times 10^{-6}$ in the $340-359 \mathrm{~nm}$ and $415-438 \mathrm{~nm}$ ranges, respectively. Such low RMS requires acquisition of $>10^{10}$ photons and takes $\sim 40-50$ min with our light-efficient instrument (Fig. 5). Figure 6 demonstrates that incorporating high light-throughput optics is key to realizing such low RMS in our setup: a single day of data collected in mode 2 was analyzed using reference spectra that differed in the time difference to the analyzed data. As the time difference is increased beyond few $10 \mathrm{~min}$, the RMS is observed to increase.

The effect of detector non-linearity has been actively suppressed in these tests by controlling the target saturation level within narrow bounds of $5 \%$. However, the temperature of the slit is expected to vary on a time scale at which heat fluxes equilibrate in our system (few $10 \mathrm{~min}$ ), and the results in Fig. 6 are generally consistent with variations in the line shape broadening (see Sect. 3.2, Table 2). We conclude that the effect of line shape broadening is most likely to explain the empirical observation of increasing RMS with increasing time difference between two spectra (Fig. 6), though other factors may contribute as well. 


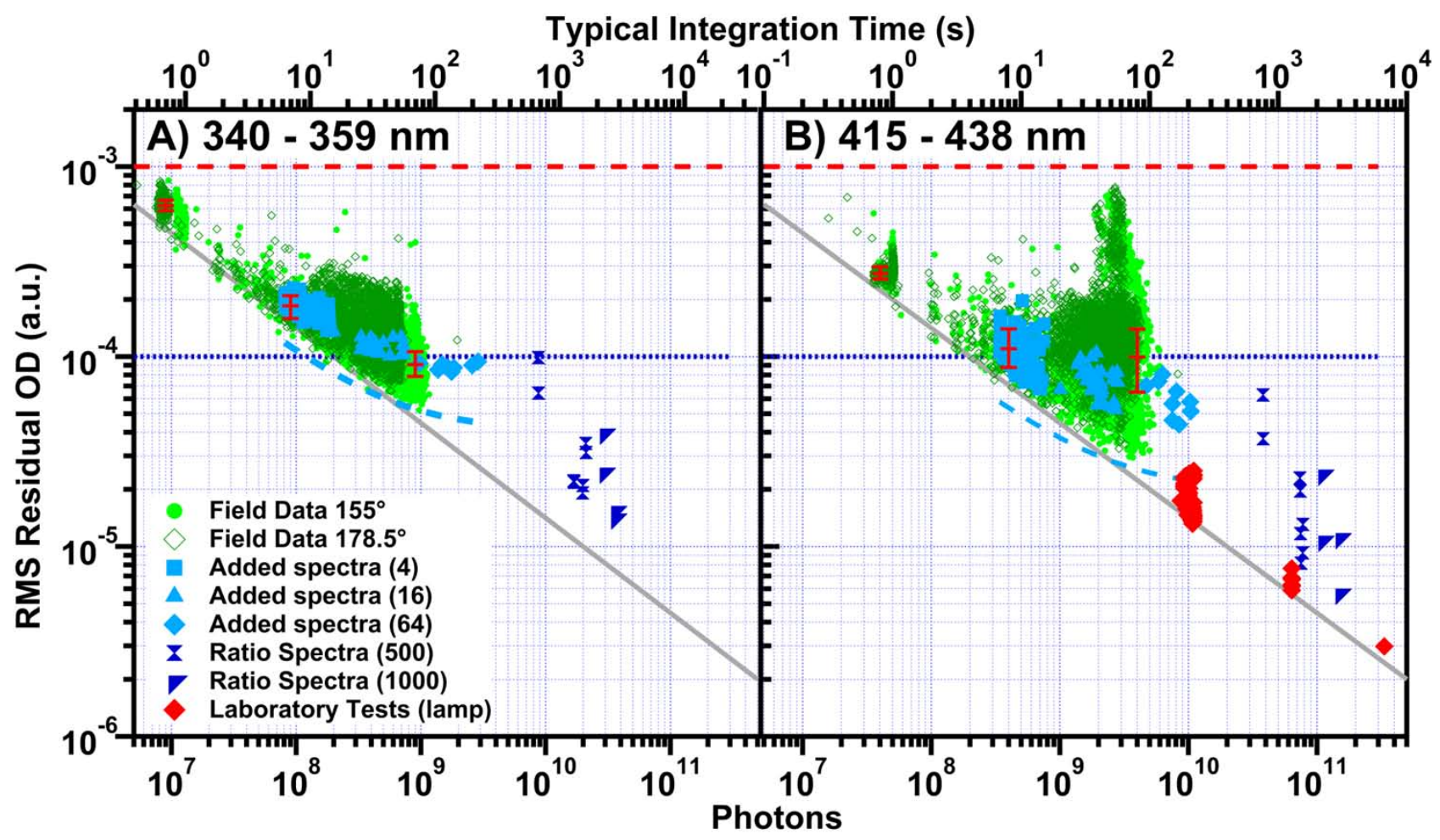

Fig. 5. Comparison of experimental and theoretical RMS noise vs. photon counting statistics for data collected between 3 March and 25 May 2010, July 2010, and April 2011. (A) For the BrO evaluation range (340-359 nm). (B) For the IO evaluation range (415-438 nm), except for the laboratory tests with a tungsten lamp which were analyzed between $440-465 \mathrm{~nm}$. Horizontal lines indicate typical RMS values of other MAX-DOAS instruments: (red dashed line) Mini-MAX-DOAS $\left(10^{-3}\right.$ RMS); (blue dotted line) research grade MAX-DOAS (10 ${ }^{-4}$ RMS). Actual field measurement data is depicted for the $155^{\circ}$ and $178.5^{\circ}$ viewing angles, (solid light green circles and open dark green diamonds, respectively) from the spring 2010. Field tests from the July 2010 period are depicted with the blue markers. Light blue indicates only co-added spectra ( $155^{\circ}$ elevation angle): 4 spectra (squares), 16 spectra (triangles), and 64 spectra (diamonds). Dark blue indicates co-added ratio spectra ( $155^{\circ}$ elevation angle): 500 ratios (hourglasses); 1000 ratios (triangles pointing up and to the left). The laboratory tests are the red diamonds. The theoretical noise for all the measurement scenarios are the gray horizontal line and the light blue horizontal line. The light blue lines were calculated with a fixed count number for the reference, which was $4 \times 10^{9}$ photons, while the grey line was calculated assuming the same number of photons in the analyzed and reference spectrum. The red horizontal lines represent the median values for the field measurements with the whiskers containing the 25 th and 75 th percentile. The top x-axis reflects typical integration times to collect the corresponding number of photons (on bottom $\mathrm{x}$-axis) for this instrument, which was calculated based on a typical value for the $60 \mathrm{~s}$ data of $8 \times 10^{8}$ and $3 \times 10^{9}$ photons in the UV and visible regions, respectively.

\section{Field measurements of halogen oxides}

The CU GMAX-DOAS instrument was deployed at two different field sites in the coastal panhandle of Florida during 2009-2010 (Fig. 1d). It operated at the first site, the South Eastern Aerosol Research (SEARCH) network site Operation Landing Field \#7 (OLF) (Hansen et al., 2003), from March to May 2009. The current measurement site is a US Environmental Protection Agency (EPA) facility in Gulf Breeze, FL $(\sim 10 \mathrm{~km}$ southeast of Pensacola, FL). The EPA site is located $\sim 1 \mathrm{~km}$ from the ocean and there is a large bay area $\sim 4 \mathrm{~km}$ to the North. The instrument has been operating at this site for the time periods May-September 2009, March-May 2010, and July 2010-February 2011.

\subsection{Measurement results}

At the inland site OLF, we measured $\mathrm{NO}_{2}, \mathrm{O}_{4}, \mathrm{CHOCHO}$, and $\mathrm{HCHO}$ on a regular basis and IO on a few select days. $\mathrm{BrO}$ was never detected above the detection limit, likely because both $\mathrm{NO}$ and $\mathrm{NO}_{2}$ readily react with $\mathrm{BrO}$, forming reservoir species that can build up in the presence of high concentrations of $\mathrm{NO}_{\mathrm{x}}$. Hence, the instrument was moved at the end of May 2009 to the EPA site located in Gulf Breeze, FL. At the coastal EPA site, the following viewing angles from ground level with respect to the northern horizon were applied: $0.8^{\circ}, 1.5^{\circ}, 3.8^{\circ}, 10^{\circ}, 25^{\circ}, 80^{\circ}, 155^{\circ}, 170^{\circ}, 176.2^{\circ}$, $178.5^{\circ}$, and $179.2^{\circ}$ and each elevation angle utilized a fixed integration time of $60 \mathrm{~s}$. These measurements allowed us to measure both to the north over the bay between Pensacola 
Table 4. Summary of the cross-sections used for each of the different analysis settings during this study.

\begin{tabular}{|c|c|}
\hline Cross-Sections & Summary of analyses \\
\hline $\begin{array}{l}\mathrm{O}_{3} T=223 \mathrm{~K} \\
\text { Bogumil et al. (2003) }\end{array}$ & $\mathrm{a}, \mathrm{b}, \mathrm{c}, \mathrm{d}, \mathrm{e}, \mathrm{f}, \mathrm{g}, \mathrm{h}, \mathrm{i}, \mathrm{j}$ \\
\hline $\begin{array}{l}\mathrm{O}_{3} T=243 \mathrm{~K} \\
\text { Bogumil et al. (2003) }\end{array}$ & $a, b, c, g, h$, \\
\hline $\begin{array}{l}\mathrm{NO}_{2} T=220 \mathrm{~K} \\
\text { Vandaele et al. (1997) }\end{array}$ & $\mathrm{g}, \mathrm{h}$ \\
\hline $\begin{array}{l}\mathrm{NO}_{2} T=294 \mathrm{~K} \\
\text { Vandaele et al. (1997) }\end{array}$ & $a, b, c, d, e, f, g, h, i, j$ \\
\hline $\mathrm{O}_{4}$ Hermans (2002) & $\mathrm{a}, \mathrm{b}, \mathrm{c}, \mathrm{e}, \mathrm{f}, \mathrm{g}, \mathrm{h}, \mathrm{i}$ \\
\hline IO Hönninger (1999) & $\mathrm{d}, \mathrm{h}, \mathrm{j}$ \\
\hline $\begin{array}{l}\text { CHOCHO } \\
\text { Volkamer et al. (2005) }\end{array}$ & $\mathrm{e}$ \\
\hline $\begin{array}{l}\mathrm{H}_{2} \mathrm{O} \\
\text { Rothman et al. (2005) }\end{array}$ & $\mathrm{d}, \mathrm{e}, \mathrm{f}, \mathrm{h}, \mathrm{j}$ \\
\hline $\begin{array}{l}\mathrm{BrO} \\
\text { Wilmouth et al. (1999) }\end{array}$ & $\mathrm{a}, \mathrm{b}, \mathrm{c}, \mathrm{g}, \mathrm{i}$ \\
\hline $\begin{array}{l}\text { HCHO Meller } \\
\text { and Moortgat (2000) }\end{array}$ & $\mathrm{a}, \mathrm{b}, \mathrm{c}, \mathrm{g}, \mathrm{i}$ \\
\hline Ring & $a, b, c, d, e, f, g, h, i, j$ \\
\hline
\end{tabular}

a: MAX-DOAS measurements (HCHO range: $337-359 \mathrm{~nm}$ ); b: MAX-DOAS measurements (BrO range: $340-359 \mathrm{~nm}$ ); c: MAX-DOAS measurements (O4 range (UV): 352 $387 \mathrm{~nm}$ ); d: MAX-DOAS measurements (IO range: $415-438 \mathrm{~nm}$ ); e: MAX-DOAS measurements (CHOCHO range: $434-460 \mathrm{~nm}$ ); f: MAX-DOAS measurements (O4 range (VIS): $462-485 \mathrm{~nm}$ ); g: Field tests of summed spectra $(340-359 \mathrm{~nm})$; h: Field tests of summed spectra $(415-438 \mathrm{~nm})$; i: Field tests of ratioed and summed spectra (340$359 \mathrm{~nm})$; j: Field tests of ratioed and summed spectra $(415-438 \mathrm{~nm})$.

and Gulf Breeze and to the south over the Gulf of Mexico. Measurements from 10 weeks at the EPA site (period from 11 March through 25 May 2010) are further discussed here.

During this spring 2010 period the instrument measured 54862 individual spectra $(\sim 4600$ full sequences of elevation angles) of which $87 \%$ were recorded at SZA $<80$ degrees; an RMS filter (RMS $<4 \times 10^{-4}$ ) was applied to filter outliers $(8 \%$ in the $\mathrm{HCHO}$ spectral range, $2 \%$ in the CHO$\mathrm{CHO}$ spectral range). We detected significant $\mathrm{BrO}$ in $0.7 \%$ of the spectra, IO in $\sim 42 \%$, $\mathrm{HCHO}$ in $\sim 65 \%$, $\mathrm{CHOCHO}$ in $\sim 32 \%, \mathrm{NO}_{2}$ in $\sim 73 \%$, and $\mathrm{O}_{4}$ in $\sim 81 \%$. Figures 7 and 8 show spectral proof for the measurement of these trace gases (Table 4) and Figs. 9 and 10 depict time series of the dSCDs for these trace gases from the period between 3 April and 8 April 2010. For all absorbers other than $\mathrm{BrO}$, the detection limit was taken as the 2-sigma noise, which roughly corresponds to 6 times the DOAS fit error (Stutz and Platt, 1996). In the case of $\mathrm{BrO}$, an equivalent RMS noise factor was determined to encompass $>98 \%$ of the negative values for each elevation angle, this factor was used to determine the detection limit. These factors varied between 1.5 and 2.1 times the RMS noise. The average detection limits were approximately $3 \times 10^{13}$ molec cm$^{-2}, 1.3 \times 10^{13} \mathrm{molec}$ $\mathrm{cm}^{-2}, 4.9 \times 10^{15}$ molec $\mathrm{cm}^{-2}, 4.1 \times 10^{14}$ molec $\mathrm{cm}^{-2}$, and

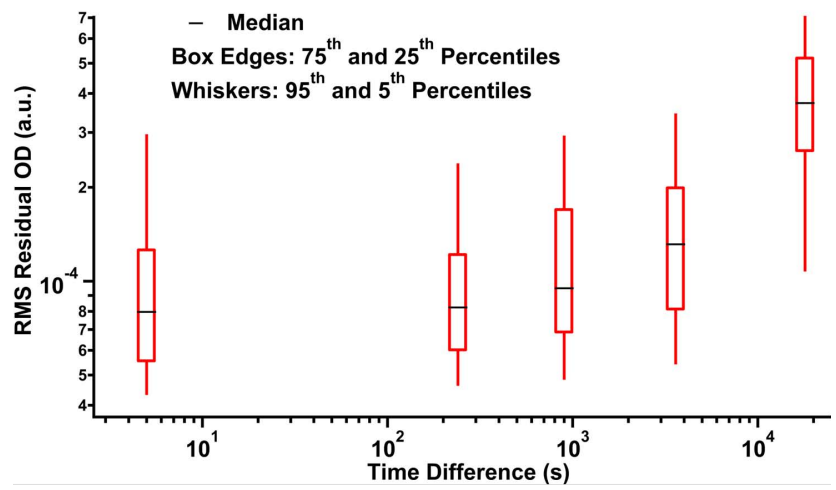

Fig. 6. RMS as a function of time difference between the spectrum analyzed and the reference. The black lines represent the median, the box edges are the $25 \%$ and $75 \%$ quartiles, and the whiskers are the $5 \%$ and $95 \%$ quartiles. In general, using a reference taken close in time to the spectrum analyzed provides better RMS values.

$1.5 \times 10^{15}$ molec $\mathrm{cm}^{-2}$ for $\mathrm{BrO}, \mathrm{IO}, \mathrm{HCHO}, \mathrm{CHOCHO}$, and $\mathrm{NO}_{2}$ respectively.

For IO the measured dSCD decrease with increasing elevation angle. We conclude that IO is mostly located in the MBL. Similarly, most BrO appears to be located in the MBL, but the split in dSCD with elevation angle is less clear. As expected, for both gases the majority of significant data was measured from the southern facing elevation angles suggesting that the coastal or open ocean air masses tend to be more enriched in the halogen oxides relative to those over the land. Radiative transfer calculations were performed in order to determine air mass factors (AMFs) to convert the measured dSCDs into VCDs, but it was found that due to uncertainty in the vertical distribution of these trace gases that using a geometric approximation was sufficient $^{2}$. So, using geometric AMFs to convert dSCDs from the $25^{\circ}$ (over land) and $155^{\circ}$ (over ocean) viewing angles to tropospheric VCDs we calculate daytime $\left(\mathrm{SZA}<80^{\circ}\right.$ ) average VCDs of significant data as $\sim 2 \times 10^{13}$ molec $\mathrm{cm}^{-2}$ for $\mathrm{BrO}$, and $\sim 8 \times 10^{12} \mathrm{molec} \mathrm{cm}^{-2}$ for IO. HCHO, CHO$\mathrm{CHO}$ and $\mathrm{NO}_{2}$ were also observed in the MBL with daytime average VCDs of $\sim 1 \times 10^{16}$ molec $\mathrm{cm}^{-2}, \sim 4 \times 10^{14}$ molec $\mathrm{cm}^{-2}$ and $\sim 3 \times 10^{15}$ molec $\mathrm{cm}^{-2}$, respectively.

Field studies (Peleg et al., 2007; Lindberg et al., 2002), laboratory studies (Donohoue et al., 2006), quantum calculations (Goodsite et al., 2004; Cremer et al., 2008; Balabanov et al., 2003; Tossell, 2003), and modeling studies (Holmes et al., 2006, 2009; Selin et al., 2007) consistently suggest

\footnotetext{
${ }^{2}$ Authors wish to note that the use of geometric AMFs for this calculation is a simplification of the radiative transfer process. We have carried out full radiative transfer calculations that varied in the assumptions about the $\mathrm{BrO}$ vertical distribution and find this simplification equally represents the uncertainty arising from the lack of knowledge about the true $\mathrm{BrO}$ vertical distribution aloft. The calculated $\mathrm{BrO}$ VCDs can contain errors on the order of $30 \%$ or more.
} 


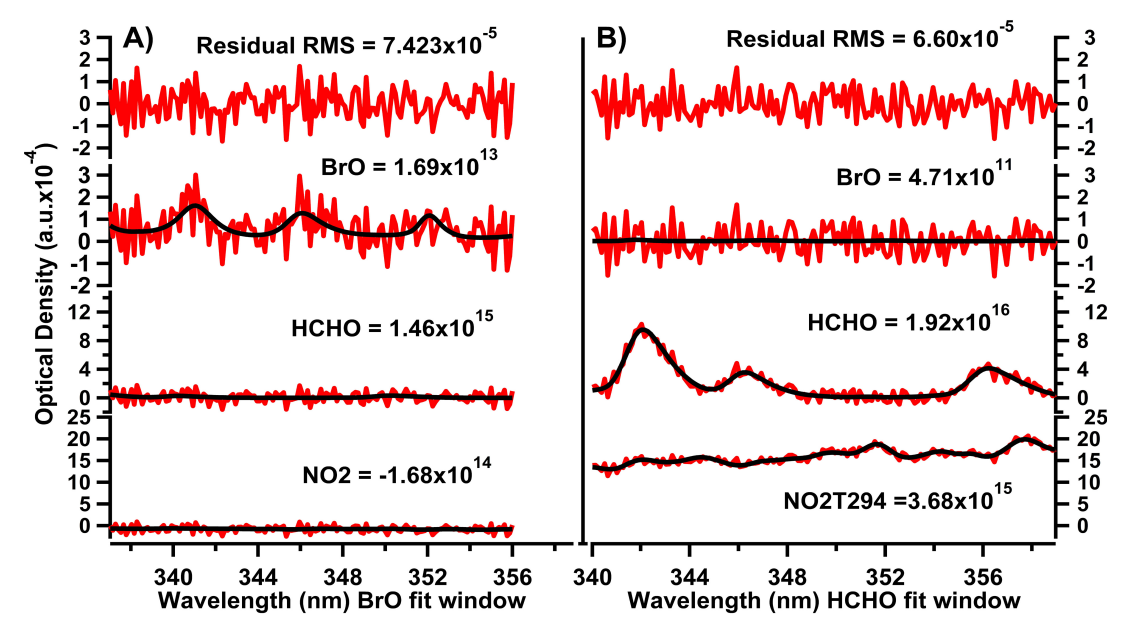

Fig. 7. Spectral proof for the detection of $\mathrm{BrO}$ and $\mathrm{HCHO}$. All spectra were analyzed for $\mathrm{BrO}$ in the $340-359 \mathrm{~nm}$ range and for $\mathrm{HCHO}$ in the 337-359 nm range. (A): the BrO fit is from 2 April 2010 at 19:36 UTC in the $155^{\circ}$ viewing angle, and (B): the HCHO fit is from $8 \mathrm{May} 2010$ at 20:28 UTC in the $25^{\circ}$ viewing angle.

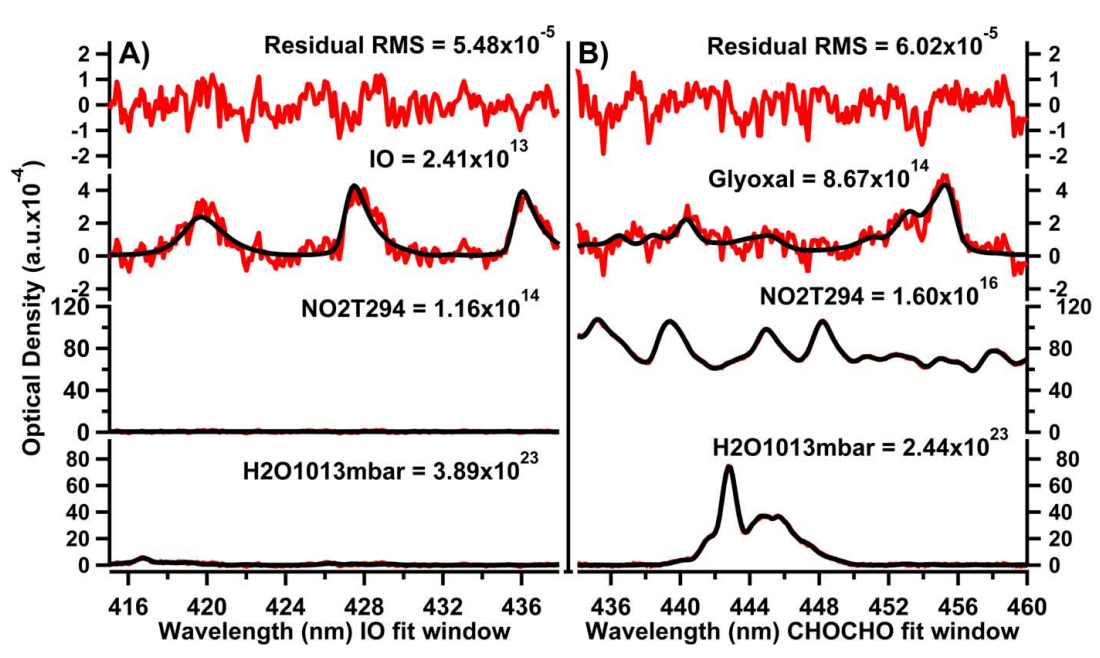

Fig. 8. Spectral proof for the detection of IO and CHOCHO. Spectra were analyzed for IO in the $415-438 \mathrm{~nm}$ range, while the range of 434-460 nm was used for CHOCHO. (A): the IO fit is from 3 April 2010 at 18:42 UTC in the $179.2^{\circ}$ viewing angle, and (B): the CHOCHO fit is from 23 March 2010 at 19:23 UTC in the $3.8^{\circ}$ viewing angle.

that a significant conversion of $\mathrm{Hg}^{0}$ to $\mathrm{Hg}^{2+}$ and possibly mercury bound to particles (PHg) (Murphy et al., 2006) may be attributed to reactive halogens. Despite the growing evidence supporting the role of halogen species, to date most global mercury models still use $\mathrm{OH}$ and $\mathrm{O}_{3}$ chemistry for the conversion of GEM to GOM (e.g., Bergan and Rodhe 2001; Selin et al., 2007). These models can reproduce the diurnal patterns of GOM but fail to reproduce the amplitude in GOM. This requires that they infer additional oxidants must exist. First attempts to represent bromine chemistry in models (Holmes et al., 2006) resulted in an atmospheric lifetime of GEM against conversion to GOM of 1.4 to $1.7 \mathrm{yr}$ (and possibly as short as $0.5 \mathrm{yr}$ ), indicating that oxidation by atomic bromine would be an important and possibly dominant global pathway for oxidation and deposition of atmospheric mercury. Only small amounts of bromine radicals, equivalent to $<2 \mathrm{ppt}$ of $\mathrm{BrO}$ are relevant to explain observed trends in GOM (Holmes et al., 2009). Our measurements provide first experimental evidence for the presence of halogen oxides in the marine boundary near Pensacola, FL.

For a systematic characterization of the $\mathrm{BrO}$ vertical distribution in the MBL and FT, we propose that further RMS reduction will increase the frequency with which $\mathrm{BrO}$ tropospheric column amounts can be detected. However, the height resolution of a ground-based instrument is limited. For BrO located above $6 \mathrm{~km}$ altitude, tropospheric and stratospheric $\mathrm{BrO}$ become entangled, and the accuracy of tropospheric $\mathrm{BrO}$ measurements becomes limited by the need 


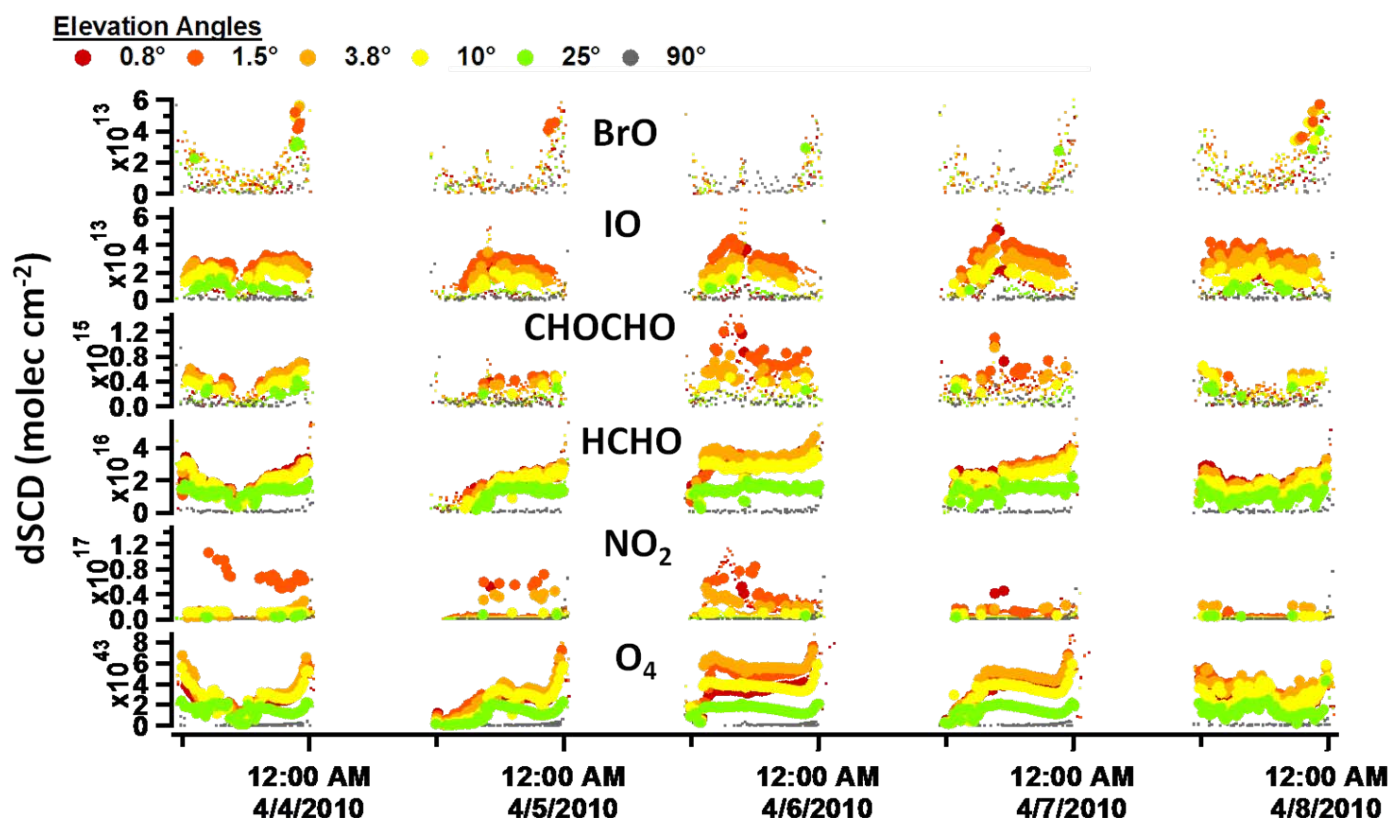

Fig. 9. Time series of the dSCDs for $\mathrm{BrO}$, IO, CHOCHO, $\mathrm{HCHO}, \mathrm{NO}_{2}$, and $\mathrm{O}_{4}$ between 3 April and 8 April 2010 (times are in UTC). This plot is for viewing directions overlooking the bay area.The large circles for each elevation angle represent statistically significant measurements, while the small dots are measurements that do not meet the significance criteria. The average fit errors from the WinDOAS analysis for these elevation angles were $9.8 \times 10^{12}$ molec cm ${ }^{-2}, 2.6 \times 10^{12}$ molec cm $^{-2}, 1.2 \times 10^{14} \mathrm{molec} \mathrm{cm}^{-2}, 1.9 \times 10^{15} \mathrm{molec} \mathrm{cm}^{-2}$, and $1.6 \times 10^{14}$ molec $\mathrm{cm}^{-2}$ for $\mathrm{BrO}, \mathrm{IO}, \mathrm{CHOCHO}, \mathrm{HCHO}$, and $\mathrm{NO}_{2}$, respectively.

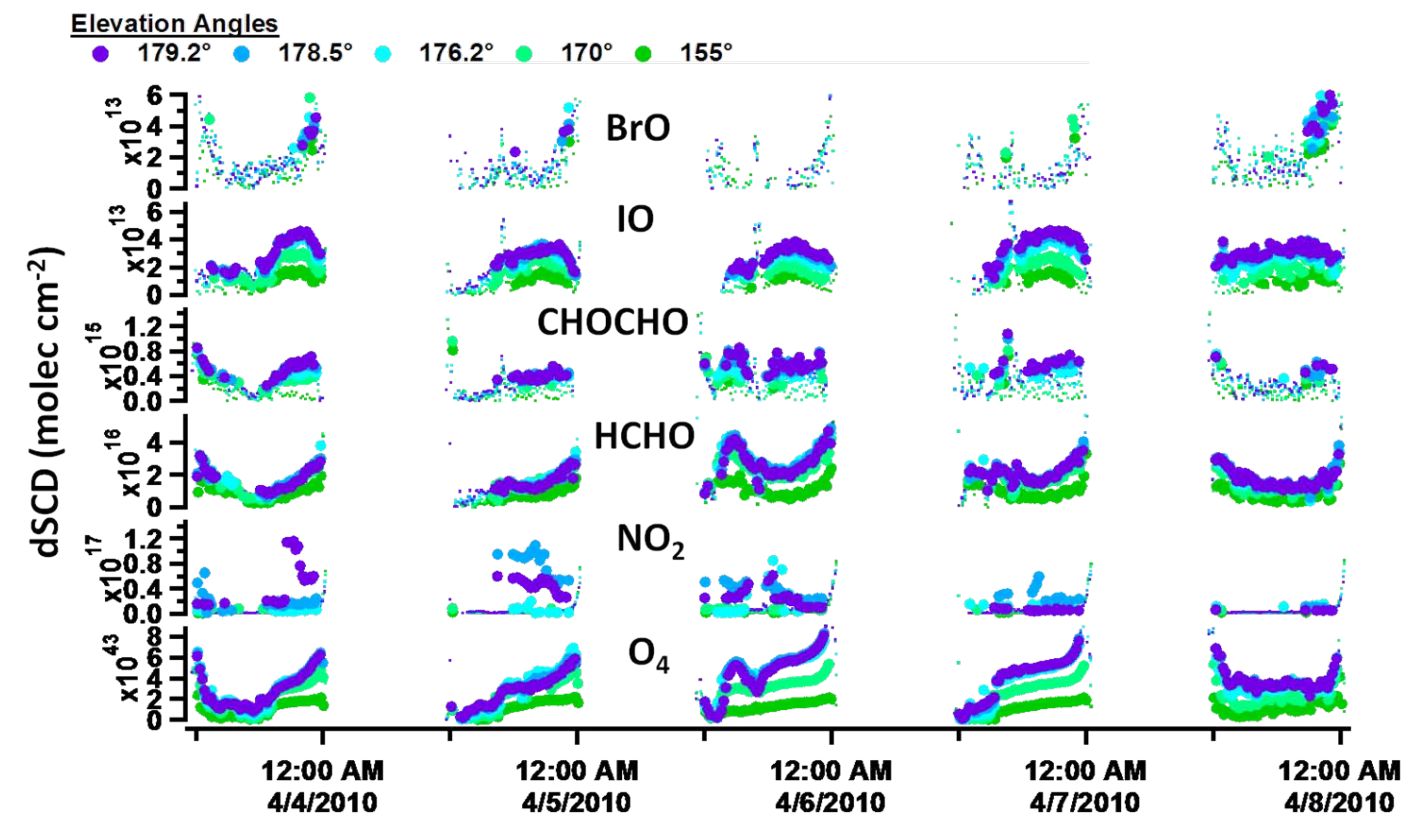

Fig. 10. Time series of the dSCDs for BrO, IO, $\mathrm{CHOCHO}, \mathrm{HCHO}, \mathrm{NO}_{2}$, and $\mathrm{O}_{4}$ between 3 April and 8 April 2010 (times are in UTC). This plot is for viewing directions overlooking the open ocean. The large circles for each elevation angle represent statistically significant measurements, while the small dots are measurements that do not meet the significance criteria. The average fit errors from the WinDOAS analysis for these elevation angles were $7.9 \times 10^{12}$ molec cm ${ }^{-2}, 2.2 \times 10^{12}$ molec cm$^{-2}, 1.1 \times 10^{14} \mathrm{molec} \mathrm{cm}^{-2}, 1.9 \times 10^{15} \mathrm{molec} \mathrm{cm}^{-2}$, and $1.3 \times 10^{14}$ molec $\mathrm{cm}^{-2}$ for $\mathrm{BrO}, \mathrm{IO}, \mathrm{CHOCHO}, \mathrm{HCHO}$, and $\mathrm{NO}_{2}$, respectively. 
to make assumptions about a stratospheric $\mathrm{BrO}$ profile. A solution to this quandary exists by using Airborne MAXDOAS, or MAX-DOAS from high mountain tops, since the MAX-DOAS technique is always maximally sensitive to absorbers located at or near (within a few $\mathrm{km}$ ) the instrument altitude (Volkamer et al., 2009; Bruns et al., 2004; Heue et al., 2005). However, ground based halogen oxide measurements by the CU GMAX-DOAS provide cost-effective means to infer the column abundance of halogen oxide radicals, and can present useful constraints for the halogen atom concentration available to destroy tropospheric ozone and oxidize GEM to GOM.

\subsection{Discussion of RMS limitations of field measurements}

As is shown in Fig. 5, the CU GMAX-DOAS instrument is capable of RMS noise of $3 \times 10^{-5}\left(440 \mathrm{~nm}, 4 \times 10^{9}\right.$ photons) and $6 \times 10^{-5}\left(350 \mathrm{~nm}, 1 \times 10^{9}\right.$ photons) comparing $60 \mathrm{~s}$ atmospheric measurements collected at different elevation angles. This is in good agreement (within 20\%) with the expected photon shot noise if reference photon noise is considered (comparison to the grey line in Fig. 5). Such low RMS is, however, not reached on a routine basis. RMS typically ranges from $6 \times 10^{-5}-1.4 \times 10^{-4}(440 \mathrm{~nm}$, $4 \times 10^{9}$ photons), and $8 \times 10^{-5}-1 \times 10^{-4}\left(350 \mathrm{~nm}, 1 \times 10^{9}\right.$ photons), with a slightly higher median RMS at visible wavelengths, but close to $1 \times 10^{-4}$ in both spectral ranges. RMS of $1 \times 10^{-4}$ is reached on a routine basis by our instrument within $10 \mathrm{~s}$ at $440 \mathrm{~nm}$, and within $40 \mathrm{sec}$ at $350 \mathrm{~nm}$. At longer integration times RMS becomes essentially independent of the number of co-added photons, wavelength range, and depends only weakly on the elevation angle $\left(5 \times 10^{-5}\right.$ higher for $1.5^{\circ}$ vs. $25^{\circ}$ ), yet - despite higher photon count - is higher at visible wavelengths than in the UV. In the further we discuss whether changing instrument properties or the representation of atmospheric state are limiting RMS.

For our field data the time difference between a lower elevation angle spectrum and its zenith reference is $\sim 330$ s, i.e., significantly shorter than the time difference of $\sim 2000 \mathrm{~s}$ at which the median RMS exceeds $1 \times 10^{-4}$ in Fig. 6. Over such short time scales the $\mathrm{RMS}_{\mathrm{FWHM}}$ as characterized in Sect. 3.2 (Table 2) is expected to be $<5 \times 10^{-5}$ at $350 \mathrm{~nm}$, and $<1 \times 10^{-5}$ at $450 \mathrm{~nm}$, and is not limiting RMS for most of our data. From Sect. 3.4 and Fig. 4, it follows that intensity changes of $12.5 \%$ over the course of acquisition of a single spectrum, coupled with a detector non-linearity of $1 \%$ causes $\mathrm{RMS}_{\mathrm{NLin}}$ of $10^{-4}$ at $440 \mathrm{~nm}$. This $\mathrm{RMS}_{\mathrm{NLin}}$ can be artificially reduced (by a factor of six) from fitting an intensity offset spectrum (slightly less reduction is expected for fitting a Ring spectrum). Our systematic control of target saturation provides alternative means to systematically eliminate $\mathrm{RMS}_{\mathrm{NLin}}$ at any target saturation level for practical purposes. In the measurements depicted in Fig. 5, the target saturation is actively controlled within $\pm 5 \%$, i.e., the maximum possible intensity difference is $10 \%$ (actual intensity variations were $\sim 2 \%$ for the cases considered here). It follows from Fig. $4 \mathrm{~b}$ and $\mathrm{d}$ that $\mathrm{RMS}_{\mathrm{NLin}}$ is $<7 \times 10^{-6}$ and $<1 \times 10^{-5}$ for the $345-360 \mathrm{~nm}$ and $425-440 \mathrm{~nm}$ ranges, respectively (with Offset and Ring being fitted in the analysis of our field data). Based on these findings, and consistent with the RMS $<10^{-4}$ values that are observed in Fig. 5, we can rule out that $\mathrm{RMS}_{\mathrm{FWHM}}$ and $\mathrm{RMS}_{\mathrm{NLin}}$ are factors that limit RMS in our field data.

Given that our instrument is capable of RMS much lower than $10^{-4}$ (Sect. 3.5, Fig. 5) we conclude that our hardware is unlikely the cause for the RMS limitations observed in the analysis of field data. We believe that it must be our representation of the atmospheric state that is limiting RMS. These factors could be bound to our limited knowledge of spectroscopic parameters of literature cross-sections (uncertain wavelength calibration, unknown temperature dependencies). In an attempt to bind this uncertainty, we estimate the effect of uncertain wavelength pixel mapping on RMS using the $\mathrm{NO}_{2}$ molecule and our Table 3 as an example. The highest wavelength precision is typically achieved by recording laboratory cross-sections using a Fourier Transform Spectrometer (FTS), for which the uncertainty in the wavelength calibration is $\sim 0.05 \mathrm{~cm}^{-1}$ (unless special precautions are taken to cross-calibrate wavelength against absolute wavelength standards before and after each spectrometer configuration/beamsplitter change). At $450 \mathrm{~nm}$, or $2222 \mathrm{~cm}^{-1}$, this translates into $0.001 \mathrm{~nm}$ uncertainty in the wavelength calibration of the FTS recorded absorption crosssection spectrum, slightly less at shorter wavelengths. At a typical dispersion of spectrometers used in MAX-DOAS applications $\left(0.1 \mathrm{~nm}\right.$ pixel $\left.^{-1}\right)$, this corresponds to an uncertainty in the wavelength pixel mapping of the convoluted reference spectrum of $\sim 0.01$ pixels at $450 \mathrm{~nm}$. Residual structures occur if strong absorbers like Fraunhofer lines and $\mathrm{NO}_{2}$ are forced onto identical wavelength pixel mappings. Results in Table 3 were scaled according to the differences in optical densities, $\delta$, between Fraunhofer lines and $\mathrm{NO}_{2}$. For a $\mathrm{NO}_{2} \mathrm{dSCD}$ of $1.5 \times 10^{17}$ molec $\mathrm{cm}^{-2}$ the average scaling factor $\delta_{\mathrm{FH}} / \delta_{\mathrm{NO}_{2}}$ is 4.3 and 2.6 for the listed Vis and UV wavelength ranges, respectively. This corresponds to a RMS of $4 \times 10^{-5}$ and $1 \times 10^{-4}$ for 0.01 pixel uncertainty, which is in principle comparable to the RMS limitations observed in this work. This $\mathrm{NO}_{2}$ dSCD represents an upper limit of the observed dSCD in our field data. Further, the observed RMS depends only very weakly on the elevation angle in our field data. RMS increases by $\sim 50 \%$ comparing $25^{\circ}$ and $1.5^{\circ}$ elevation angle spectra, for which the air mass factor increases by a factor of $\sim 3$. It thus appears that the RMS limitations are less likely to be caused by numerical limitations in our representation of atmospheric absorbers located in the boundary layer, which would leverage the full air mass factor advantage in the lower elevation angles. More likely, other factors play a role in our setup. Nonetheless, the characterization of wavelength pixel mapping at an accuracy of better 
0.01 pixels seems pre-requite to lowering RMS further, in addition to high photon counts and stable instruments. The effects described in Sects. 3.1, 3.2, 3.3 and 3.4 are examples that can limit the accuracy at which the wavelength pixel mapping is known, yet do not seem to limit our setup. This is the direct result of the active measures taken to stabilize the temperature of the rack/slit, and to control the target saturation of our detector within narrow bounds.

We cannot rule out that an imperfect representation of scattering processes, i.e., non-linear rotational Ring caused by a combination of aerosol scattering and second order molecular scattering (Langford et al., 2007), or missing reference spectra (i.e., vibrational Raman scattering of $\mathrm{N}_{2}$ and $\mathrm{O}_{2}$ ), are responsible for the higher than expected RMS. Vibrational Raman scattering has been suggested to play a role for zenith sky DOAS measurements of stratospheric absorbers at high SZA (Platt et al., 1997), as well as for liquid water in the oceans (Vountas et al., 2003). Vibrational Raman scattering on gas-phase molecules is today not typically considered in the analysis of MAX-DOAS spectra, which treat only the rotational component of Raman scattering to calculate the Ring reference spectrum (Chance and Spurr, 1997; Vountas et al., 1998; Platt and Stutz, 2008; Wagner et al., 2009). We are unaware of a discussion of vibrational Raman scattering by gas-phase molecules for tropospheric absorbers measured by MAX-DOAS, where in addition to $\mathrm{N}_{2}$ and $\mathrm{O}_{2}$ also $\mathrm{H}_{2} \mathrm{O}$ could play a role. The Stokes Raman vibrational scattering cross sections of $\mathrm{N}_{2}$, and $\mathrm{O}_{2}$ are about 50, and 100 times weaker than their rotational Raman scattering homologues, yet they are 15 times stronger for $\mathrm{H}_{2} \mathrm{O}$ (Fenner et al., 1973; Bendtsen, 1974; Penney and Lapp, 1976; Avila et al., 1999, 2003; Brodersen and Bendtsen, 2003). In the tropical marine boundary layer $\mathrm{O}_{2}$ and $\mathrm{H}_{2} \mathrm{O}$ add $\sim 30 \%$ and $<15 \%$ relative to $\mathrm{N}_{2}$ to the vibrational Raman scattering intensity. Several factors in our data make us believe that the lack of an explicit treatment of the vibrational Raman effect is partly responsible for the RMS limitations that we observe: (1) RMS limitations are only observed when comparing spectra between different elevation angles, but not when comparing solar stray light spectra at the same elevation angle; (2) RMS limitations consistently depend only weakly on the elevation angle, as is expected for a limitation caused by a scattering process, but not necessarily for an absorber; (3) a typical rotational Ring $\delta$ ranges from essentially zero to $\sim 0.006$ on a clear day, and the vibrational Stokes Ring $\delta$ can thus reach $1.2 \times 10^{-4}$. This optical density is comparable to the RMS limit we find near $440 \mathrm{~nm}$; (4) the vibrational Stokes Raman scattering of $\mathrm{N}_{2}$ (vibrational frequency, $\omega_{\mathrm{N}_{2}}=2330 \mathrm{~cm}^{-1}$ ) has the effect to shift a Fraunhofer line located at $398 \mathrm{~nm}$ to $438.6 \mathrm{~nm}$ (Stokes Raman scattering); in fact, rotation-vibrational Raman scattering will distribute $398 \mathrm{~nm}$ photons over the wavelength range from 434 to $444 \mathrm{~nm}$. We observe larger RMS deviations from theory at longer wavelengths (see Fig. 5, and Sect. 3.5). Most likely not a single factor can be isolated to explain our observed RMS at high photon counts. Further studies are needed to leverage the full potential sensitivity of our CU GMAX-DOAS instrument.

\section{Conclusions and outlook}

The instrument properties and the uncertainties surrounding the RMS limited retrieval of $\mathrm{BrO}$ and $\mathrm{IO}$ from solar stray light MAX-DOAS spectra were explored. A novel CU GMAX-DOAS instrument is described, and characterized, and found capable of achieving RMS $<10^{-5}$ without any limitations other than photon shot noise in laboratory tests with a tungsten light source, as well as with solar stray light. As a pre-requisite for achieving this low RMS we identified that the detector non-linearity of our state-of-the-art CCD detector, as well as changes in optical resolution due to small temperature variations are two key factors that can limit DOAS evaluations of solar stray light spectra at RMS $\sim 10^{-4}$. Both factors were addressed and minimized in the design of the CU GMAX-DOAS instrument.

In a first field deployment, the CU GMAX-DOAS instrument routinely achieved RMS in the range of $8 \times 10^{-5}<\mathrm{RMS}<1.0 \times 10^{-4}$ and $6 \times 10^{-5}<\mathrm{RMS}<1.4$ $\times 10^{-4}$ in all elevation angles, and in the $340-359 \mathrm{~nm}$ and $415-438 \mathrm{~nm}$ ranges, respectively. We present measurements of $\mathrm{BrO}, \mathrm{IO}, \mathrm{CHOCHO}, \mathrm{HCHO}, \mathrm{NO}_{2}$, and $\mathrm{O}_{4}$. These are the first measurements of $\mathrm{BrO}$, IO and $\mathrm{CHOCHO}$ over the Gulf of Mexico, providing direct evidence for the presence these halogen oxides in the MBL. BrO in the MBL indicates the availability of bromine atoms as oxidants for elemental mercury. The relevance of IO in the MBL on the observed elevated mercury wet deposition has been little studied and remains uncertain.

A detailed characterization of RMS noise limitations in our instrument finds that the hardware is not currently limiting RMS at high photon counts. Yet deviations from the expected RMS are observed, and found to be larger in the 415$438 \mathrm{~nm}$ range, than at $340-359 \mathrm{~nm}$, despite the higher photon count at the longer wavelengths. The representation of atmospheric state is likely limited by the need to represent vibrational Raman scattering (see Sect. 4.2), though other factors inherent to our retrieval algorithm cannot be fully ruled out. To investigate whether it is numerical limitations inherent to our retrieval algorithm or limited information about external analysis inputs that is currently limiting the representation of the atmospheric state, the operation of our hardware with an active DOAS system (e.g., LP-DOAS or CEDOAS) without Fraunhofer lines, Ring effect, etc., seems to be promising, see e.g., Thalman and Volkamer, 2010. The CU GMAX-DOAS hardware has the potential to lower the attainable RMS further, with according benefits for instrument sensitivity and atmospheric discovery.

Acknowledgements. The instrument was developed with support from EPRI's Technology Innovation program (EP-P27450/C13049). Additional support from EPRI 
(EP-P32238/C14974), NSF-CAREER (ATM-0847793) and CU Boulder startup funds is gratefully acknowledged.

Edited by: M. Weber

\section{References}

Atkinson, R., Baulch, D. L., Cox, R. A., Crowley, J. N., Hampson, R. F., Hynes, R. G., Jenkin, M. E., Rossi, M. J., and Troe, J.: Evaluated kinetic and photochemical data for atmospheric chemistry: Volume III gas phase reactions of inorganic halogens, Atmos. Chem. Phys., 7, 981-1191, doi:10.5194/acp-7-981-2007, 2007.

Avila, G., Fernandez, J. M., Mate, B., Tejeda, G., and Montero, S.: Ro-vibrational Raman cross sections of water vapor in the $\mathrm{OH}$ stretching region, J. Mol. Spectrosc., 196, 77-92, doi:10.1006/jmsp.1999.7854, 1999.

Avila, G., Tejeda, G., Fernandez, J. M., and Montero, S.: The rotational Raman spectra and cross sections of $\mathrm{H}_{2} \mathrm{O}, \mathrm{D}_{2} \mathrm{O}$, and HDO, J. Mol. Spectrosc., 220, 259-275, doi:10.1016/S00222852(03)00123-1, 2003

Balabanov, N. B. and Peterson, K. A.: Mercury and reactive halogens: The thermochemistry of $\mathrm{Hg}+\left\{\mathrm{Cl}_{2}, \mathrm{Br}_{2}\right.$, $\mathrm{BrCl}, \mathrm{ClO}$, and $\mathrm{BrO}\}$, J. Phys. Chem. A, 107, 7465-7470, doi:10.1021/jp035547p, 2003.

Bendtsen, J.: The rotational and rotation-vibrational Raman spectra of ${ }^{14} \mathrm{~N}_{2},{ }^{14} \mathrm{~N}^{15} \mathrm{~N}$, and ${ }^{15} \mathrm{~N}_{2}$, J. Raman Spectrosc., 2, 133-145, doi: 10.1002/jrs.1250020204, 1974.

Bergan, T. and Rodhe, H.: Oxidation of elemental mercury in the atmosphere; Constraints imposed by global scale modelling, J. Atmos. Chem., 40, 191-212, doi:10.1023/A:1011929927896, 2001.

Bobrowski, N., Hönninger, G., Galle, B., and Platt, U.: Detection of Bromine Monoxide in a Volcanic Plume, Nature, 423, 273-276, doi:10.1038/nature01625, 2003.

Bogumil, K., Orphal, J., Homann, T., Voigt, S., Spietz, P., Fleischmann, O. C., Vogel, A., Hartmann, M., Kromminga, H., Bovensmann, H., Frerick, J., and Burrows J. P.: Measurements of molecular absorption spectra with the SCIAMACHY pre-flight model: Instrument characterization and reference data for atmospheric remote-sensing in the 230-2380 nm region, J. Photoch. Photobio. A, 157, 167-184, doi:10.1016/S1010-6030(03)000625, 2003.

Brodersen, S. and Bendtsen, J.: The incoherent Raman spectrum of ${ }^{16} \mathrm{O}_{2}$ molecular constants from all experimental data, J. Molec. Spectrosc., 219, 248-257, doi:10.1016/S0022-2852(03)00101-2, 2003.

Bruns, M., Buehler, S. A., Burrows, J. P., Heue, K. P., Platt, U., Pundt, I., Richter, A., Rozanov, A., Wagner, T., and Wang, P.: Retrieval of profile information from airborne multiaxis UVvisible skylight absorption measurements, Appl. Opt., 43, 44154426, doi:10.1364/AO.43.004415, 2004.

Chance, K. V. and Spurr, R. J. D.: Ring effect studies: Rayleigh scattering, including molecular parameters for rotational Raman scattering, and the Fraunhofer spectrum, Appl. Opt., 36, 52245230, 1997.

Cremer, D., Kraka, E., and Filatov, M.: Bonding in mercury molecules described by the normalized elimination of the small component and coupled cluster theory, Chem. Phys. Chem., 9, 2510-2521, doi:10.1002/cphc.200800510, 2008.

Donohoue, D. L., Bauer, D., Cossairt, B., and Hynes, A. J.: Temperature and pressure dependent rate coefficients for the reaction of $\mathrm{Hg}$ with $\mathrm{Br}$ and the reaction of $\mathrm{Br}$ with $\mathrm{Br}$ : A pulsed laser photolysis-pulsed laser induced fluorescence study, J. Phys. Chem. A, 110, 6623-6632, doi:10.1021/jp054688j, 2006.

Fayt, C. and van Roozendael, M.: WinDoas 2.1 - Software User Manual, Brussels: BIRA-IASB, 2001.

Fenner, W. R., Hyatt, H. A., Kellam, J. M., and Porto, S. P. S.: Raman cross-section of some simple gases, J. Opt. Soc. Am., 63, 73-77, doi:10.1364/JOSA.63.000073, 1973.

Frieß, U., Hollwedel, J., König-Langlo, G., Wagner, T., and Platt, U.: Dynamics and chemistry of tropospheric bromine explosion events in the Antarctic coastal region, J. Geophys. Res., 109, D06305, doi:10.1029/2003JD004133, 2004.

Frieß, U., Deutschmann, T., Gilfedder, B. S., Weller, R., and Platt, U.: Iodine monoxide in the Antarctic snowpack, Atmos. Chem. Phys., 10, 2439-2456, doi:10.5194/acp-10-2439-2010, 2010.

Goodsite, M. E., Plane, J. M. C., and Skov, H.: A theoretical study of the oxidation of $\mathrm{Hg}_{0}$ to $\mathrm{HgBr}_{2}$ in the troposphere, Environ. Sci. Technol., 38, 1772-1776, doi:10.1021/es034680s, 2004.

Hausmann, M. and Platt, U.: Spectroscopic measurement of bromine oxide and ozone in the high Arctic during Polar Sunrise Experiment 1992, J. Geophys. Res., 99, 25399-25413 doi:10.1029/94JD01314, 1994.

Hansen, D. A., Edgerton, E. S., Hartsell, B. E., Jansen, J. J., Kandasamy, N., Hidy, G. M., and Blanchard, C. L.: The southeastern aerosol research and characterization study: Part 1 - overview, J. Air Waste Manage., 53, 1460-1471, 2003.

Heckel, A., Richter, A., Tarsu, T., Wittrock, F., Hak, C., Pundt, I., Junkermann, W., and Burrows, J. P.: MAX-DOAS measurements of formaldehyde in the Po-Valley, Atmos. Chem. Phys., 5, 909918, doi:10.5194/acp-5-909-2005, 2005.

Herman, J., Cede, A., Spinei, E., Mount, G., Tzortziou, M., and Abuhassan, $\mathrm{N}$.: $\mathrm{NO}_{2}$ column amounts from ground-based Pandora and MFDOAS spectrometers using the direct-sun DOAS technique: Intercomparisons and application to OMI validation, J. Geophys. Res., 114, D13307, doi:10.1029/2009JD011848, 2009.

Hermans, C.: Measurement of absorption cross sections and spectroscopic molecular parameters: $\mathrm{O}_{2}$ and its collisional induced absorption, available at: http://spectrolab.aeronomie.be/o2.htm, 2002.

Heue, K.-P., Richter, A., Bruns, M., Burrows, J. P., v. Friedeburg, C., Platt, U., Pundt, I., Wang, P., and Wagner, T.: Validation of SCIAMACHY tropospheric $\mathrm{NO}_{2}$-columns with AMAXDOAS measurements, Atmos. Chem. Phys., 5, 1039-1051, doi:10.5194/acp-5-1039-2005, 2005.

Holmes, C. D., Jacob, D. J., and Yang, X.: Global lifetime of elemental mercury against oxidation by atomic bromine in the free troposphere, Geophys. Res. Lett., 33, L20808, doi:10.1029/2006GL027176, 2006.

Holmes, C. D., Jacob, D. J., Mason, R. P., and Jaffe, D. A.: Sources and deposition of reactive gaseous mercury in the marine atmosphere, Atmos. Environ., 43, 2278-2285, doi:10.1016/j.atmosenv.2009.01.051, 2009.

Hönninger, G.: Referenzspektren reaktiver Halogenverbindungen für DOAS-Messungen, diploma thesis, University of Heidelberg, 
1999.

Hönninger, G.: Halogen Oxide Studies in the Boundary layer by Multi Axis Differential Optical Absorption Spectroscopy and Active longpath-DOAS, PhD thesis, Heidelberg of University, Germany, 2002.

Hönninger, G. and Platt, U.: Observations of $\mathrm{BrO}$ and its vertical distribution during surface ozone depletion at Alert, Atmos. Environ., 36, 2481-2489, doi:10.1016/S1352-2310(02)00104-8, 2002.

Hönninger, G., von Friedeburg, C., and Platt, U.: Multi axis differential optical absorption spectroscopy (MAX-DOAS), Atmos. Chem. Phys., 4, 231-254, doi:10.5194/acp-4-231-2004, 2004.

Ibrahim, O., Shaiganfar, R., Sinreich, R., Stein, T., Platt, U., and Wagner, T.: Car MAX-DOAS measurements around entire cities: quantification of NOx emissions from the cities of Mannheim and Ludwigshafen (Germany), Atmos. Meas. Tech., 3, 709-721, doi:10.5194/amt-3-709-2010, 2010.

Irie, H., Kanaya, Y., Akimoto, H., Iwabuchi, H., Shimizu, A., and Aoki, K.: First retrieval of tropospheric aerosol profiles using MAX-DOAS and comparison with lidar and sky radiometer measurements, Atmos. Chem. Phys., 8, 341-350, doi:10.5194/acp-8341-2008, 2008.

Irie, H., Kanaya, Y., Akimoto, H., Iwabuchi, H., Shimizu, A., and Aoki, K.: Dual-wavelength aerosol vertical profile measurements by MAX-DOAS at Tsukuba, Japan, Atmos. Chem. Phys., 9, 2741-2749, doi:10.5194/acp-9-2741-2009, 2009.

Kraus, S.: DOASIS - A Framework Design for DOAS, Shaker Verlag, University of Heidelberg, Germany, 2006.

Kurucz, R. L., Furenlid, I., Brault, J., and Testerman, L.: Solar Flux Atlas from 296 to $1300 \mathrm{~nm}$, Technical Report, National Solar Observatory, 1984.

Langford, A. O., Schofield, R., Daniel, J. S., Portmann, R. W., Melamed, M. L., Miller, H. L., Dutton, E. G., and Solomon, S.: On the variability of the Ring effect in the near ultraviolet: understanding the role of aerosols and multiple scattering, Atmos. Chem. Phys., 7, 575-586, doi:10.5194/acp-7-575-2007, 2007.

Lindberg, S. E., Brooks, S., Lin, C. J., Scott, K. J., Landis, M. S., Stevens, R. K., Goodsite, M., and Richter, A.: Dynamic oxidation of gaseous mercury in the Arctic troposphere at polar sunrise, Environ. Sci. Technol., 36, 1245-1256, doi:10.1021/es0111941, 2002.

Meller, R. and Moortgat, G. K.: Temperature dependence of the absorption cross sections of formaldehyde between 223 and 323 $\mathrm{K}$ in the wavelength range $225-375 \mathrm{~nm}$, J. Geophys. Res., 105, 7089-7102, doi:10.1029/1999JD901074, 2000.

Murphy, D. M., Thomson, D. S., and Mahoney, T. M. J.: In situ measurements of organics, meteoritic material, mercury, and other elements in aerosols at 5 to 19 kilometers, Science, 282, 1664-1669, doi:10.1126/science.282.5394.1664, 1998.

Penney, C. M. and Lapp, M.: Raman scattering crosssections for water vapor, J. Opt. Soc. Am., 66, 422-425, doi:10.1364/JOSA.66.000422, 1976.

Platt, U.: Differential optical absorption spectroscopy (DOAS), in: Air Monitoring by Spectroscopic Techniques, Chem. Anal. Ser., edited by: Sigrist, M. W., John Wiley \& Sons, Inc., New York, 127, 1994.

Platt, U. and Perner, D.: Direct measurement of atmospheric $\mathrm{CH}_{2} \mathrm{O}$, $\mathrm{HNO}_{2}, \mathrm{O}_{3}, \mathrm{NO}_{2}$, and $\mathrm{SO}_{2}$ by Differential Optical-Absorption in the near UV, J. Geophys. Res.-Oc. Atm., 85, 7453-7458,
doi:10.1029/JC085iC12p07453, 1980.

Platt, U. and Stutz, J.: Differential Optical Absorption spectroscopy, Principles and Applications, (Physics of Earth and Space Environments), Springer, Berlin, 597, 2008.

Platt, U., Marquard, L., Wagner, T., and Perner, D.: Corrections for zenith scattered light DOAS, Geophys. Res. Lett., 24, 17591762, doi:10.1029/97GL01693, 1997.

Peleg, M., Matveev, V., Tas, E., Luria, M., Valente, R. J., and Olbrist, D.: Mercury depletion events in the troposphere in midlatitudes at the Dead Sea, Israel, Environ. Sci. Technol., 41, 7280-7285, doi:10.1021/es070320j, 2007.

Roscoe, H. K., Van Roozendael, M., Fayt, C., du Piesanie, A., Abuhassan, N., Adams, C., Akrami, M., Cede, A., Chong, J., Clémer, K., Frieß, U., Gil Ojeda, M., Goutail, F., Graves, R., Griesfeller, A., Grossmann, K., Hemerijckx, G., Hendrick, F., Herman, J., Hermans, C., Irie, H., Johnston, P. V., Kanaya, Y., Kreher, K., Leigh, R., Merlaud, A., Mount, G. H., Navarro, M., Oetjen, H., Pazmino, A., Perez-Camacho, M., Peters, E., Pinardi, G., Puentedura, O., Richter, A., Schönhardt, A., Shaiganfar, R., Spinei, E., Strong, K., Takashima, H., Vlemmix, T., Vrekoussis, M., Wagner, T., Wittrock, F., Yela, M., Yilmaz, S., Boersma, F., Hains, J., Kroon, M., Piters, A., and Kim, Y. J.: Intercomparison of slant column measurements of $\mathrm{NO}_{2}$ and $\mathrm{O}_{4}$ by MAX-DOAS and zenith-sky UV and visible spectrometers, Atmos. Meas. Tech., 3, 1629-1646, doi:10.5194/amt-3-1629-2010, 2010.

Rothman, L. S., Jacquemart, D., Barbe, A., Benner, D. C., Birk, M., Brown, L. R., Carleer, M. R., Chackerian, C., Chance, K., Coudert, L. H., Dana, V., Devi, V. M., Flaud, J.-M., Gamache, R. R., Goldman, A., Hartmann, J.-M., Jucks, K. W., Maki, A. G., Mandin, J.-Y., Massie, S. T., Orphal, J., Perrin, A., Rinsland, C. P., Smith, M. A. H., Tennyson, J., Tolchenov, R. N., Toth, R. A., Vander Auwera, J., Varanasi, P., and Wagner, G.: The HITRAN 2004 molecular spectroscopic database, J. Quant. Spectrosc. RA., 96, 139-204, doi:10.1016/j.jqsrt.2004.10.008, 2005.

Selin, N. E., Jacob, D. J., Park, R. J., Yantosca, R. M., Strode, S., Jaegle, L., and Jaffe, D.: Chemical cycling and deposition of atmospheric mercury: Global constraints from observations, J. Geophys. Res.-Atmos., 112, D02308, doi:10.1029/2006JD007450, 2007.

Schönhardt, A., Richter, A., Wittrock, F., Kirk, H., Oetjen, H., Roscoe, H. K., and Burrows, J. P.: Observations of iodine monoxide columns from satellite, Atmos. Chem. Phys., 8, 637653, doi:10.5194/acp-8-637-2008, 2008.

Sinreich, R.: Multi-Axis Differential Optical Absorption Spectroscopy Measurements in Polluted Environments. Ph. D. thesis, University of Heidelberg, 2008.

Sinreich, R., Coburn, S., Dix, B., and Volkamer, R.: Ship-based detection of glyoxal over the remote tropical Pacific Ocean, Atmos. Chem. Phys., 10, 11359-11371, doi:10.5194/acp-1011359-2010, 2010.

Stutz, J. and Platt, U.: Numerical analysis and estimation of the statistical error of differential optical absorption spectroscopy measurements with least-squares methods, Appl. Opt., 35, 60416053, doi:10.1364/AO.35.006041, 1996.

Stutz, J., Ackermann, R., Fast, J. D., and Barrie, L.: Atmospheric reactive chlorine and bromine at the Great Salt Lake, Utah, Geophys. Res. Lett., 29, 1380, doi:10.1029/2002GL014812, 2002.

Thalman, R. and Volkamer, R.: Inherent calibration of a blue 
LED-CE-DOAS instrument to measure iodine oxide, glyoxal, methyl glyoxal, nitrogen dioxide, water vapour and aerosol extinction in open cavity mode, Atmos. Meas. Tech., 3, 1797-1814, doi:10.5194/amt-3-1797-2010, 2010.

Theys, N., Van Roozendael, M., Hendrick, F., Fayt, C., Hermans, C., Baray, J.-L., Goutail, F., Pommereau, J.-P., and De Mazière, M.: Retrieval of stratospheric and tropospheric $\mathrm{BrO}$ columns from multi-axis DOAS measurements at Reunion Island $\left(21^{\circ} \mathrm{S}\right.$, $56^{\circ}$ E), Atmos. Chem. Phys., 7, 4733-4749, doi:10.5194/acp-74733-2007, 2007.

Tossell, J. A.: Calculation of the energetic for oxidation of gasphase elemental $\mathrm{Hg}$ by $\mathrm{Br}$ and $\mathrm{BrO}$, J. Phys. Chem. A, 107, 7804-7808, doi:10.1021/jp030390m, 2003.

Vandaele, A. C., Hermans, C., Simon, P. C., Carleer, M., Colin, R., Fally, S., Merienne, M.-F., Jenouvrier, A., and Coquart, B.: Measurements of the $\mathrm{NO}_{2}$ absorption cross-section from 42000 $\mathrm{cm}^{-1}$ to $10000 \mathrm{~cm}^{-1}(238$ to $1000 \mathrm{~nm})$ at $220 \mathrm{~K}$ and $294 \mathrm{~K}$, J. Quant. Spectrosc. Radiat. Transfer, 59, 171-184, 1997.

Vigouroux, C., Hendrick, F., Stavrakou, T., Dils, B., De Smedt, I., Hermans, C., Merlaud, A., Scolas, F., Senten, C., Vanhaelewyn, G., Fally, S., Carleer, M., Metzger, J.-M., Mller, J.-F., Van Roozendael, M., and De Mazière, M.: Ground-based FTIR and MAX-DOAS observations of formaldehyde at Réunion Island and comparisons with satellite and model data, Atmos. Chem. Phys., 9, 9523-9544, doi:10.5194/acp-9-9523-2009, 2009.

Volkamer, R., Spietz, P., Burrows, J. P., and Platt, U.: Highresolution absorption cross-section of Glyoxal in the UV/vis and IR spectral ranges, J. Photoch. Photobio. A, 172, 35-46. doi:10.1016/j.jphotochem.2004.11.011, 2005.

Volkamer, R., Coburn, S., Dix, B., and Sinreich, R.: MAX-DOAS observations from ground, ship, and research aircraft: maximizing signal-to-noise to measure "weak" absorbers, in: SPIE Proceedings "Ultraviolet and Visible Ground- and Space-based Measurements, Trace Gases, Aerosols and Effects, San Diego, 2-9 August 2009, 746203, doi:10.1117/12.826792, 2009.
Vountas, M., Rozanov, V. V., and Burrows, J. P.: Ring Effect: Impact of rotational Raman scattering on radiative transfer in earth's atmosphere, J. Quant. Spectrosc. Ra., 60, 943-961, doi:10.1016/S0022-4073(97)00186-6, 1998.

Vountas, M., Richter, A., Wittrock, F., and Burrows, J. P.: Inelastic scattering in ocean water and its impact on trace gas retrievals from satellite data, Atmos. Chem. Phys., 3, 1365-1375, doi:10.5194/acp-3-1365-2003, 2003.

Wagner, T., Dix, B., von Friedeburg, C., Frieß, U., Sanghavi, S., Sinreich, R., and Platt, U.: MAX-DOAS $\mathrm{O}_{4}$ measurements: A new technique to derive information on atmospheric aerosols. Principles and information content, J. Geophys. Res. 109, D22205, doi:10.1029/2004JD004904, 2004.

Wagner, T., Deutschmann, T., and Platt, U.: Determination of aerosol properties from MAX-DOAS observations of the Ring effect, Atmos. Meas. Tech., 2, 495-512, doi:10.5194/amt-2-4952009, 2009.

Wagner, T., Ibrahim, O., Sinreich, R., Frieß, U., von Glasow, R., and Platt, U.: Enhanced tropospheric BrO over Antarctic sea ice in mid winter observed by MAX-DOAS on board the research vessel Polarstern, Atmos. Chem. Phys., 7, 3129-3142, doi:10.5194/acp-7-3129-2007, 2007.

Wilmouth, D. M., Hanisco, T. F., Donahue, N. M., and Anderson, J. G.: Fourier transform ultraviolet spectroscopy of the $\mathrm{A}^{2} \Pi_{3 / 2}^{\leftarrow} \mathrm{X}^{2} \Pi_{3 / 2}$ transition of BrO, J. Phys. Chem., 103, 89358945, 1999.

Wittrock, F., Oetjen, H., Richter, A., Fietkau, S., Medeke, T., Rozanov, A., and Burrows, J. P.: MAX-DOAS measurements of atmospheric trace gases in Ny-Ålesund - Radiative transfer studies and their application, Atmos. Chem. Phys., 4, 955-966, doi:10.5194/acp-4-955-2004, 2004. 